\title{
Bargaining Frictions, Labor Income Taxation, and Economic Performance*
}

\author{
Stéphane Auray ${ }^{\dagger} \quad$ Samuel Danthine ${ }^{\ddagger}$
}

January 12, 2010

\begin{abstract}
This paper is an attempt to explain differences in economic performance between a subset of OECD countries. We classify countries in terms of their degree of rigidity in the labor market, and use a matching model with labor/leisure choice, bargaining frictions, and labor income taxation to capture these rigidity differences. Added flexibility improves economic performance in different ways depending on whether income taxation is high or low. Feeding income taxation rates estimated from the countries at hand, we find that the model is able to replicate the observed rigidity levels. The model is also shown to reproduce well cross-country differences in non-employment population ratios and the share of part-time jobs. In the absence of rigidity differences, taxation shows little promise to replicate cross-country differences, as it has insufficient quantitative effects on production and productivity. However, the interaction of rigidity and income taxation is crucial in explaining the empirical patterns of the non-employment rate and of the share of parttime jobs.
\end{abstract}

Keywords: models of search and matching, bargaining frictions, economic performance, labor market institutions, part-time jobs, labor market rigidities.

JEL Class.: E24; J22; J30; J41; J50; J64

${ }^{*}$ This is a substantially revised version of "Bargaining Frictions and Hours Worked", IZA DP 1722 . We are grateful to the editor, Zvi Eckstein, and the referees for insightful comments that lead to a substantial revision of the paper. In addition, we would like to thank Mark Bils, Olivier Charlot, Jean-Pierre Danthine, Martin Gervais, Paul Gomme, Jeremy Greenwood, Tatyana Koreshkova, Lance Lochner, Miguel Molico, Javier Ortega, Louis Phaneuf, Peter Rupert, José Silva, Antoine Terracol, Etienne Wasmer, seminar participants at the following universities: Western Ontario, Concordia, Cergy Pontoise, Sherbrooke, Autonoma de Madrid, Granada, Southampton, Lausanne, Málaga, Jaume I, participants at the WEGMaNS conference in Rochester, at the SED and ESEM summer meetings, at the NIEPA V conference at Queens, and at the First Advances in the Analysis of Labor Markets with Frictions Workshop in Málaga for helpful comments on this or the previous version of the paper. The traditional disclaimer applies. This work was supported in part by the French Agence Nationale de la Recherche, the Fonds Québecois de la Recherche sur la Société et la Culture, as well as by the Junta de Andaluciá through grants SEJ-552 and SEJ-01645. The second author wishes to thank the Departamento de Teoriá y Historia Económica of Universidad de Málaga for their hospitality.

${ }^{\dagger}$ Universités Lille Nord de France (ULCO), MESHS (USR 3185), GREDI, Université de Sherbrooke and CIRPÉE, Canada. Email: stephane.auray@gmail.com

${ }^{\ddagger}$ Université du Québec à Montréal and CIRPÉE. Email: danthine.samuel@gmail.com 


\section{Introduction}

It is arguable that the bulk of cross-country variations in economic performance in the OECD can be linked to differences in labor market organization. In this paper, we focus on two labor market features, rigidity in contracting and labor income taxation. We show that they are indeed of first order importance in explaining differences in economic performance amongst European countries as well as between European countries and the US. The indicators of economic performance we focus on are GDP per capita, GDP per hour, hours worked per capita, non-employment, and the proportion of part-time jobs. We frame our analysis in a matching model in which risk-averse workers and risk-neutral firms vary in productivity and face idiosyncratic shocks to productivity. Workers value leisure, and workers and firms bargain over wages and over the length of the work day. We show that four elements of our model are necessary to explain the observed cross-country differences: heterogeneity in productivity, bargaining over the length of the workday as well as the wages, bargaining frictions, and income taxes.

These ingredients allow the model to replicate the features of economic performance well. The intuition behind the results is the following. Income taxation, all else equal, leads to a decrease in employment (and thus GDP per capita) and an increase in part-time work: pairs that would agree to a full-time contract at lower taxation levels may decide to work part-time when taxation increases. Similarly, pairs who would accept working part-time at lower taxation levels might decide not to work at all. Because of the heterogeneity in productivity, the effect of varying taxation is not the same, however, at all levels of unemployment. When unemployment is high, there are many relatively productive prospects searching. This increases the value of searching, leading searchers to be more picky in their acceptation of contracts. Hence only pairs with sufficiently high joint productivity match, and do so predominantly full-time. This dampens the effect of a high tax rate on part-time, and leads to a greater level of sorting. At higher employment levels, more and more high types are matched in equilibrium, thus lowering the quality of the pool of searchers and making searchers less picky with whom to accept. The share of part-time matches is much higher the lower the joint productivity of the pair. Differences in taxation then have great effects on part-time jobs. The level of rigidities affects part-time jobs and employment: higher rigidities decrease the value of a part-time match by lowering the probability that the pair can negotiate a full-time 
contract given the proper productivity shock. Higher rigidities thus come with lower employment, and, all else equal, a lower share of part-time work. Given this, different taxation levels will have different effects on part-time depending on the level of rigidities. In addition, an increase in unemployment can increase or decrease GDP per capita, depending on the level of sorting in the economy, level of sorting which of course is linked to the quality of the pool of searchers. Quantitatively, taxation has only a limited effect on GDP per capita and GDP per hour. However it affects employment and the share of part-time in an important way that varies at different levels of rigidity. It is the interaction of income taxation with rigidities in bargaining that differentiates economies in the model. This is crucial if one wants to replicate cross-country differences within continental Europe, where countries differ only marginally in taxation levels, but hugely in terms of economic performance. Considering both bargaining frictions and labor income taxation therefore proves to be empirically relevant to explain differences in economic performance across countries.

This paper fits in a recent literature documenting and trying to explain differences across countries in economic performance. Rogerson (2006) stresses that a combination of technological change and government intervention is the best candidate to account for the long term changes in hours worked across countries. Prescott (2003) highlights the importance of labor income taxation to explain differences in employment and hours worked between Europe (seen as mainly France) and the US; Ljungqvist and Sargent (2007) argue that, in a model similar to Prescott's, adding unemployment insurance diminishes the bite of labor income taxation. In an empirical paper, Nickell (2004) claims that while taxes do explain part of the differences, they are far from making up the entire story. Pissarides (2007) argues that productivity growth plays a big role in the evolution of hours, and is the main reason for the healthy state of labor markets in Europe in the 1960's. In addition, he shows that while taxes play a role in explaining differences in hours, it is mostly a minor one. To contrast to this literature, this paper shows that, while labor income taxation is not enough to account for cross-country differences in economic performance, including the proportion of part-time jobs, adding bargaining rigidities on both wages and hours goes a long way in explaining these differences both qualitatively and quantitatively. In fact, given income taxation corresponding to different countries, we are able to back out rigidity parameters from our model that correspond nicely to what can be seen from the data. In addition, the model is able to 
replicate well non-employment rates and relative part-time shares.

Finally, a number of papers are related to ours with regards to the modelling assumptions. Gertler and Trigari (2009) introduce staggered bargaining in a matching model with the hope of resolving the unemployment volatility puzzle (as described in Pissarides (2009)). Blazquez and Jansen (2008) propose a matching model with heterogenous agents on both sides to assess whether the market equilibrium ends up being efficient (it doesn't). Ortega (2003) uses a model with ex-post heterogeneous firms to show that the existence of a legal limits on hour choices can enhance efficiency with respect to laissez-faire. Nagypál (2005) uses potentially negative idiosyncratic shocks to the value of a job to workers in a search model and endogenous search effort to show that such a model can successfully replicate job-to-job transition data.

The paper is organized as follows. In Section 2, data on economic performance and labor market institutions are briefly presented for a set of countries. The model is described in Section 3. The economy is parameterized, and the effects of changes in the probability of recontracting and in the rate of taxation, as well as in other parameters, are presented and analyzed in Section 4. The model is then evaluated quantitatively. A final section concludes.

\section{Economic Performance and Labor Market Institutions}

Economic performance and labor market institutions are summarized for Belgium, France, Germany, the Netherlands, Spain, Italy, the UK and the US. ${ }^{1}$ For many of the variables that we are interested in, it is not possible to just separate the sample using the US-Europe divide.

\subsection{Economic Performance, a summary}

GDP per capita in the US is higher than GDP per capita in European countries, and this has been the case since 1970. While historically, unemployment was higher in the US, this has not been the case since the early eighties. Recently, two European countries, the Netherlands and the UK, have lowered their unemployment rates to the level of the US. Looking at the employment/population ratio, the US have a higher rate of employment than most European countries, the UK and the Netherlands being the exceptions once more. European countries vary a lot in the their trends: Germany, France and Belgium are coming closer to the US with

\footnotetext{
${ }^{1}$ All the data used for the purpose of this section are presented and discussed in details in Appendix A.
} 
regards to the employment/population ratio, but at varying rates and starting at different moments.

The US had more total hours than European countries in 1970, and while hours went on a downward trend in European countries, they increased or remained relatively constant in the US. Hours per capita increased in the US while it decreased in Belgium, Germany, Italy and France. In Spain, the Netherlands and the UK, hours per capita followed the latter trend until the mid 1980's but then started increasing again until recently. Controlling for workers, the situation is relatively stationary in the US and decreasing in all European countries. The evolution of employment and hours over the period at hand translates in an increase in GDP per hour in most European countries relative to the US, with the striking exception of the UK where this trend remains relatively constant. In the most recent years, however, European countries have seen a reduction in their levels of GDP per hour relative to the US. Finally, Belgium, Germany, the UK and the Netherlands have higher part time jobs than the others countries with the Netherlands undoubtedly being the champion for these types of jobs.

\subsection{Labor market setting, a summary}

The US and the UK are characterized by a high level of decentralization, a low level of coordination between unions and firms and a relatively low level of coverage. Within Europe, one can distinguish France and Germany from Belgium and the Netherlands. In France, negotiations are decentralized and not frequent, union density is low and coordination between social partners (unions, firms and the government) is weak, but collective bargaining coverage is high. In Germany, union density is low and coordination between social partners is high, but collective bargaining coverage is high and negotiations are not frequent. The Netherlands are characterized by a higher degree of centralization, more coordination and a high collective bargaining coverage with more frequent negotiations. The situation in Belgium is similar to the one in the Netherlands but with less frequent negotiations. The combination of these three elements greatly improves the flexibility of the Dutch labor market and, to a lower degree, in Belgium. In some aspects, Spain and Italy could be considered on the path to improvements in labor markets flexibility. They remain however very rigid, and are characterized by a low incidence of part time jobs. Finally, taking a look at income taxation, the US and the UK have low effective tax rates compared to the other European countries in our sample. To 
sum up, the US and the UK can be seen as low income taxation, highly flexible countries compared to France, Germany, Spain, and Italy which are characterized by both high labor market rigidities and high income taxation, while Belgium and, especially, the Netherlands stand in the middle as economies with a relatively flexible labor market but a high level of income taxation.

\section{The Model}

To show the importance of rigidities and taxation in explaining differences in economic and labor market performance, we present a model of matching in which we introduce four important characteristics that are outlined next.

\subsection{The ingredients}

Four ingredients are essential to our model. First, agents are heterogeneous and face an idiosyncratic shock to their productivity. Because of this, matches can be of different quality. This results in a situation in which high employment can translate in more or less production per hour depending on the quality of sorting in the economy. In particular, an increase in the level of unemployment has two opposite effects on production: a negative effect on production due to the fall in employment, a positive effect due to the destruction of low quality matches. Second, the labor-leisure choice enters in the bargaining process, opening the way to part-time jobs and allowing for rigidities and income taxation to crucially affect hour choices. Third, the bargaining process is subject to frictions: firms and workers engaged in a match cannot renegotiate every period, but they know the probability with which they will be allowed to bargain in the future. Given the idiosyncratic shocks they face, firms and workers may want to readjust the number of hours they work and the corresponding hourly wage. This is not always possible, however, because of the bargaining frictions. These frictions thus create a distortion in both the choice to work or not to work and in the selection of the length of the working day. Fourth, differences in labor income taxation are introduced. Taxes distort the value of employment for workers. For similar levels of rigidities, an increase in the labor income tax induces some workers to switch from full-time to part-time employment, others to abandon their full-time jobs, and still others to quit their part-time jobs. These four ingredients together with the two-sided approach combine to deliver a rich depiction of the 
labor market. The two-sided view of the labor market is both necessary for the results and justified as an assumption, since the labor market is one that is inherently heterogeneous on two sides and in which both sides search for their better option. We now proceed to lay out explicitly our economy.

\subsection{The model}

Ours is a quantitative two-sided search model with heterogeneity in both worker and firm types and idiosyncratic shocks, as proposed in Danthine (2005), extended to include labor/leisure choices and bargaining frictions. Time is discrete. The economy is inhabited by heterogeneous and infinitely-lived workers and firms. A worker's productivity level is labeled by $z \in Z=\left\{z_{1}, \ldots, z_{\mathcal{N}}\right\}$, while a firm's productivity is denoted by $x \in X=\left\{x_{1}, \ldots, x_{\mathcal{M}}\right\} .{ }^{2} \mathrm{~A}$ worker of type $z_{k}$ evolves to type $z_{l}$ with transition probability $Z(l \mid k)$. Similarly, a firm's productivity evolves from $x_{i}$ to $x_{j}$ following the transition probability $X(j \mid i)$. When searching for a worker, a firm holding a vacancy meets a worker of type $z_{k}$ with probability $\Omega_{k}$. There is no cost of posting a vacancy. Similarly, an unemployed worker meets a firm of type $x_{i}$ with probability $\Phi_{i}$. A newly matched pair $i k$ bargains over the hourly wage $w_{i k}$ and the number of per period hours $h_{i k}$. If the two find a mutually agreeable arrangement, they produce using production function $F_{i k}\left(h_{i k}, k\right)=\left(x_{i} k\right)^{\alpha}\left(h^{\mu} z_{k}\right)^{1-\alpha}$, where $k$ is the stock of capital of the firm, which does depreciate and is normalized to $1 .^{3}$ In that case, define the indicator function $I_{i k}=1$. Otherwise, they lose a productive period, have to search once more next period and $I_{i k}=0$. A previously matched pair composed of types $i k$, with previous contract $(w, h)$, evolves to $j l$ with probability $X(j \mid i) Z(l \mid k)$. With probability $\pi$, the pair can bargain over a new contract. If the two parties manage to agree on new terms, $I_{j l}=1$ and the new contract is $\left(w_{j l}, h_{j l}\right)$. Otherwise they lose a period, start searching again, and $I_{j l}=0$. With probability $(1-\pi)$, they are not allowed to recontract. In that case, either they agree to remain together, allowing one to define an indicator function $J_{j l}(w, h)=1$. If either member (or both) find that searching grants a higher value, they separate and $J_{j l}(w, h)=0$. Thus the coefficient $\pi$ is a measure of the degree of contracting stickiness in the economy and can be calibrated to match the data. This type of Poisson adjustment process is widely used in

\footnotetext{
${ }^{2}$ In numerical simulations, $\mathcal{N}=\mathcal{M}=10$.

${ }^{3}$ The stock of capital is introduced here to help us calibrating parameters at a later stage. We thank a referee for advising us to use this strategy.
} 
the macroeconomic literature. It is for instance often used to model staggered price setting behaviour, as in Calvo (1983) and the literature following that paper. Recently it has been used by Gertler and Trigari (2009) to model bargaining rigidities, as is done in our paper.

\subsection{Firms}

A firm can be in any of three situations at the beginning of a period: matched with a worker and allowed to bargain again; matched with a worker and not allowed to bargain, in which case the worker and the firm must choose whether to remain matched at the previously set conditions or to split; vacant and in negotiation with a worker. Let $V_{i}$ be the value for a firm of type $i$ of remaining vacant and $P_{i k}$ be the value of a new contract for a firm of type $i$ matched with a worker of type $k$. Finally, let $L_{i k}\left(w_{i k}, h_{i k}\right)$ be the value for a firm of type $i$ matched with a worker of type $k$ of producing under a previous contract $h_{i k}$. Then,

$$
\begin{aligned}
P_{i k}=F_{i k}\left(h_{i k}\right)-w_{i k} h_{i k} & +\beta \sum_{j} \sum_{l} X(j \mid i) Z(l \mid k)\left[\pi\left(I_{j l} P_{j l}+\left(1-I_{j l}\right) V_{j}\right)\right. \\
& \left.+(1-\pi)\left(J_{j l}\left(w_{i k}, h_{i k}\right) L_{j l}\left(w_{i k}, h_{i k}\right)+\left(1-J_{j l}\left(w_{i k}, h_{i k}\right)\right) V_{j}\right)\right] .
\end{aligned}
$$

Although complicated at first sight, this expression is straightforward. $F_{i k}\left(h_{i k}\right)-w_{i k} h_{i k}$ is just the net profit of the firm over the period. The pair $i k$ then evolves to $j l$ with probability $X(j \mid i) Z(l \mid k)$; with probability $\pi$, it can renegotiate and either decide to pursue their partnership $\left(I_{j l}=1\right)$ or not. With probability $(1-\pi)$, the pair cannot renegotiate, and must decide whether to remain in partnership at the old contract $\left(J_{j l}\left(w_{i k}, h_{i k}\right)=1\right)$ or not. The value of remaining vacant is simply given by

$$
V_{i}=\beta \sum_{j} \sum_{l} X(j \mid i) \Omega_{l}\left(I_{j l} P_{j l}+\left(1-I_{j l}\right) V_{j}\right)
$$

where $X(j \mid i) \Omega_{l}$ is the probability of evolving from type $i$ to type $j$ and to meet a worker of type $l$. Notice that a newly matched pair is always allowed to bargain. Finally,

$$
\begin{array}{rl}
L_{i k}(w, h)=F_{i k}(h)-w h+\beta \sum_{j} \sum_{l} & X(j \mid i) Z(l \mid k)\left[\pi\left(I_{j l} P_{j l}+\left(1-I_{j l}\right) V_{j}\right)\right. \\
& \left.+(1-\pi)\left(J_{j l}(w, h) L_{j l}(w, h)+\left(1-J_{j l}(w, h)\right) V_{j}\right)\right] .
\end{array}
$$

The continuation part of this expression is identical to that in (1). The first part is just the net period profits given current types and past hours and wages. 


\subsection{Workers}

A worker can be in the same three situations, and the expressions for workers' value functions are very similar to those of the firm. Denote the value of being employed at newly negotiated terms by $E$, the value of being employed at formerly negotiated terms by $T$, and the value of being unemployed by $U$. The value for a type $k$ worker of being employed by a type $i$ firm is given by

$$
\begin{aligned}
E_{i k}=u\left((1-\tau) w_{i k} h_{i k}, 1\right. & \left.-h_{i k}\right)+\beta \sum_{j} \sum_{l} X(j \mid i) Z(l \mid k)\left[\pi\left(I_{j l} E_{j l}+\left(1-I_{j l}\right) U_{l}\right)\right. \\
& \left.+(1-\pi)\left(J_{j l}\left(w_{i k}, h_{i k}\right) T_{j l}\left(w_{i k}, h_{i k}\right)+\left(1-J_{j l}\left(w_{i k}, h_{i k}\right)\right) U_{l}\right)\right] .
\end{aligned}
$$

It looks very much like equation (1), the difference being that workers have possibly non-linear utility $u(\cdot)$ and may be taxed at rate $\tau$. The value of being unemployed is just

$$
U_{k}=u(b, 1)+\beta \sum_{j} \sum_{l} Z(l \mid k) \Phi_{j}\left(I_{j l} E_{j l}+\left(1-I_{j l}\right) U_{l}\right),
$$

where $b$ is unemployment insurance. Finally, being employed by a type $i$ firm but at past hours $h$ and wage $w$ yields

$$
\begin{aligned}
T_{i k}(w, h)=u((1-\tau) w h, 1-h)+ & \beta \sum_{j} \sum_{l} X(j \mid i) Z(l \mid k)\left[\pi\left(I_{j l} E_{j l}+\left(1-I_{j l}\right) U_{l}\right)\right. \\
& \left.+(1-\pi)\left(J_{j l}(w, h) T_{j l}(w, h)+\left(1-J_{j l}(w, h)\right) U_{l}\right)\right] .
\end{aligned}
$$

\subsection{Nash Bargaining}

We now define two indicator functions, $I$ and $J$. The first follows from the bargaining problem. A firm of type $i$ and a worker of type $k$ choose earnings $e_{i k}$ and hours $h_{i k}$, with $e_{i k}=w_{i k} h_{i k}$ to maximize the product of their surpluses under the constraint that both surpluses must be non-negative:

$$
\begin{aligned}
\max _{h, e}\left[P_{i k}(e, h)-V_{i}\right]^{1-\eta} & \times\left[E_{i k}(e, h)-U_{k}\right]^{\eta}, \\
& \text { st. } \\
P_{i k}(e, h) \geqslant V_{i} \text { and } \quad & E_{i k}(e, h) \geqslant U_{k} .
\end{aligned}
$$

If a solution to this problem exists, then $I_{i k}=1$, otherwise $I_{i k}=0$. In similar fashion, $J_{i k}(e, h)=1$ if, at the terms of the last negotiated contract $(e, h)$, both firm and worker have 
a positive surplus, so that $L_{i k}(e, h) \geqslant V_{i}$ and $T_{i k}(e, h) \geqslant U_{k}$. Otherwise, if either or both prefer searching again, $J_{i k}(e, h)=0$. With the existing distribution of workers and firms and with the newly defined indicator function, it is possible to update the distributions.

\subsection{Updating the Distributions}

Updating the probability of meeting a worker or a firm of a certain type involves counting. Let $M_{i k o p}^{b}$ be the measure of pairs of type $i k$ who in the previous period were allowed to bargain and chose a contract $\left(w_{o p}, h_{o p}\right){ }^{4}$ Similarly, let $M_{i k o p}^{n}$ be the measure of pairs of type $i k$ who did not bargain in the previous period, had a previously agreed upon contract $\left(w_{o p}, h_{o p}\right)$, and remained together. Then $\sum_{o} \sum_{p}\left(M_{i k o p}^{b}+M_{i k o p}^{n}\right)$ is the measure of $i k$ pairs who were matched in the previous period. Of these worker-firm pairs, a proportion $\pi$ are allowed to renegotiate. In addition, there is a measure $\Phi_{i} \Omega_{k} N$ of $i k$ pairs who meet in the market. If they can find a mutually agreeable contract $\left(w_{i k}, h_{i k}\right)$, then they engage in production $\left(I_{i k}=1\right)$. Any pair consisting of types $i$ and $k$ evolves to types $j$ and $l$ with probability $X(j \mid i) Z(l \mid k)$. Hence, at the beginning of the next period, the measure of $j l$ pairs who were matched with contract $\left(w_{i k}, h_{i k}\right)$ is given by:

$$
M_{j l i k}^{b^{\prime}}=\left[\left(\sum_{o} \sum_{p} M_{i k o p}^{b}+M_{i k o p}^{n}\right) \pi+\Phi_{i} \Omega_{k} N\right] I_{i k} X(j \mid i) Z(l \mid k) .
$$

In somewhat similar fashion, multiplying the measure of pairs of type $i k$ who had contract $\left(w_{o p}, h_{o p}\right)$ by $(1-\pi)$ yields the measure of $i k$ firms who cannot renegotiate and have to decide whether or not to continue producing at the past contractual terms. If they decide it is worth maintaining their relationship, $J_{i k o p}=1$. The probability that they evolve to $j l$ is given by $X(j \mid i) Z(l \mid k)$. Summing over all possible $i k$ 's leads to the measure of $j l$ pairs who cannot rebargain and carry over choice $h$ from this period to the next:

$$
M_{j l o p}^{n^{\prime}}=\sum_{i} \sum_{k}\left[M_{i k o p}^{b}+M_{i k o p}^{n}\right](1-\pi) J_{i k o p} X(j \mid i) Z(l \mid k)
$$

The probability of meeting a worker of type $k$ is just the measure of unmatched workers of that type divided by the total number of unmatched workers. To obtain this, define $A_{j l}$ as the measure of $j l$ pairs who met in the previous period and did not find an agreeable contract, given that they were allowed to (re-)bargain. Similarly, define $B_{j l}$ to be the measure of pairs

\footnotetext{
${ }^{4}$ In fact, this implies they were of type $o p$ in the previous period.
} 
$j l$ who decided not to produce last period given that they could not renegotiate. These are given by

$$
A_{j l}=\sum_{i} \sum_{k}\left[\sum_{o} \sum_{p}\left(M_{i k o p}^{b}+M_{i k o p}^{n}\right) \pi+\Phi_{i} \Omega_{k} N\right]\left(1-I_{i k}\right) X(j \mid i) Z(l \mid k),
$$

and

$$
B_{j l}=\sum_{i} \sum_{k}\left[\sum_{o} \sum_{p}\left(M_{i k o p}^{b}+M_{i k o p}^{n}(1-\pi)\left(1-J_{i k o p}\right)\right)\right] X(j \mid i) Z(l \mid k) .
$$

It should be clear that the measure of unmatched workers or firms is given by the double sum

$$
N^{\prime}=\sum_{l} \sum_{j}\left(A_{j l}+B_{j l}\right)
$$

Summing $A_{j l}+B_{j l}$, for each firm type, across worker types and dividing by $N^{\prime}$ yields the distribution of vacancy types. The distribution of unemployed is obtained in similar fashion. Formally,

$$
\Phi_{j}^{\prime}=\frac{\sum_{l}\left(A_{j l}+B_{j l}\right)}{N^{\prime}}
$$

and

$$
\Omega_{l}^{\prime}=\frac{\sum_{j}\left(A_{j l}+B_{j l}\right)}{N^{\prime}}
$$

\subsection{Stationary Equilibrium}

A stationary equilibrium is a set of value functions $E, P, U, V, L, T$, distributional functions $\Phi, \Omega, M^{b}, M^{n}, N$ and indicator functions $I, J$ such that $E, P, U, V, L, T$ satisfy equations (1)(6), $I, J$ are defined by (7), and the distributions are stationary.

\section{Results}

To evaluate the model, three steps are taken. First, functional forms are given and the parameters are chosen: we parameterize the economy to match features and estimates for the US economy. Second, the properties of the numerical equilibrium and their sensitivity to parameter and policy changes are discussed. Special emphasis is put on the qualitative effects of parameter changes. Third, we put the model through the task of reproducing, quantitatively, some cross-country differences. 


\subsection{Parametrization}

Functional forms for the production function, for individual preferences and for the idiosyncratic shocks must be specified. The production function is assumed to be a Cobb-Douglas on which we impose diminishing marginal returns to hours $(\mu<1)$. Part-time work in the model is assumed to be working less than three quarters of the maximum day length. This matches the OECD definition of part-time being less than 30 hours under the assumption of a maximum work week of 40 hours. There is no overtime in our model. It is assumed every firm is endowed with one unit of non-depreciating capital, $k=1$. This allows us to link parameters $\mu$ and $\alpha$ to the factor shares of production. To sum up, the production function takes the form

$$
F_{i k}(k, h)=\left(x_{i} k\right)^{\alpha}\left(h^{\mu} z_{k}\right)^{1-\alpha},
$$

where $x_{i}$ is the firm type, $h$ the number of hours worked, and $z_{k}$ the worker type. The utility function is assumed to be

$$
u(c, h)=\frac{c^{(1-\sigma)}}{1-\sigma}+a \frac{(1-h)^{1-\nu}}{1-\nu},
$$

where $c$ is consumption, and $1-h$ is leisure. Hence $\sigma$ is the parameter of risk aversion, $a$ guides the weight of leisure in the utility function, and $\nu$ guides the marginal utility of leisure. Furthermore, we assume the idiosyncratic shocks follow an AR(1) process with mean persistence $\rho$ and deviation $\epsilon$. We discretize this process using Tauchen's method, assuming there are 10 types for both workers and firms. We now have a list of 12 parameters on which to assign numerical values: preference parameters $\beta, \sigma, a, \nu$, production parameters $\alpha, \mu$, as well as a parameter representing the weight of the firm in the bargaining process, $\eta$. In addition, we have an institutional parameter $\pi$, two policy parameters $\tau$ and $b$, and parameters guiding the idiosyncratic shocks, $\rho$ and $\epsilon$. We will use the institutional and policy parameters as free parameters. In this section, we look at the qualitative effects of changes in these parameters on economic performance. In the following section, we use them to try to replicate features of the data on cross-country differences in economic performance. This leaves us with 9 parameters to calibrate. We wish to have a quarter as the model period, and to do so set the discount factor $\beta=0.99$. Risk aversion is set to a relative standard level: $\sigma=1$, implying log-utility in consumption. Note that we need to assume a tiny level of home production to keep the log-utility well behaved when unemployment insurance is assumed away. 
Figure 1: Employment Share

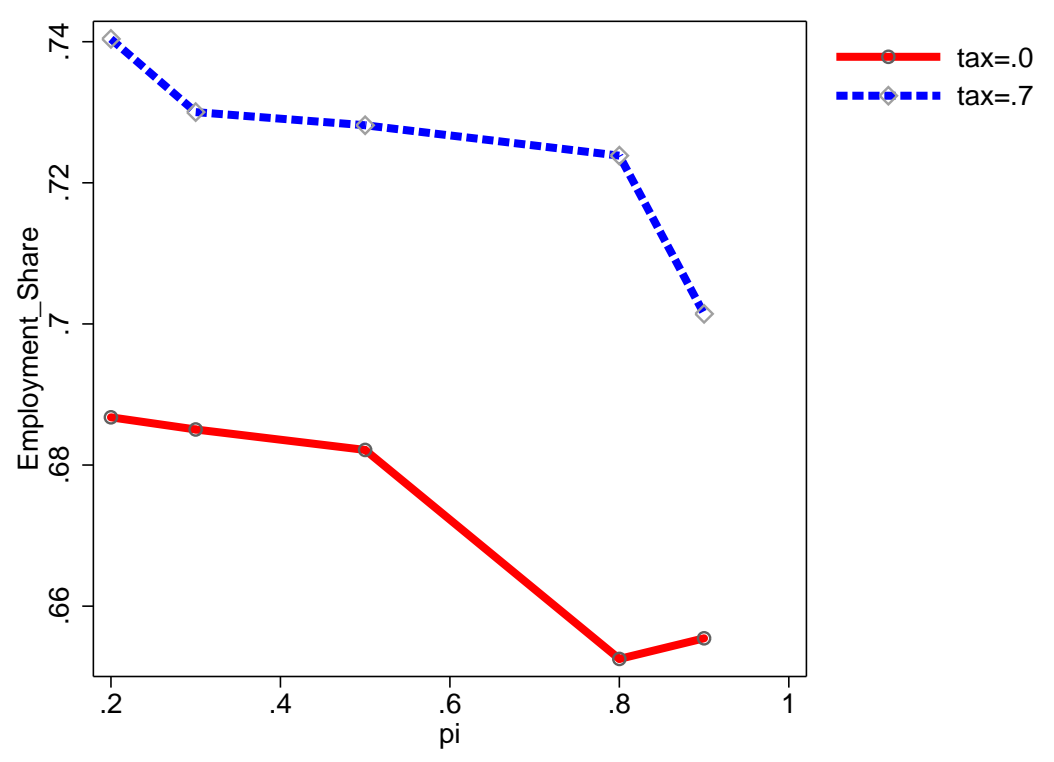

We fix the production parameters to obtain a labor income share that stays in the $[0.65,0.75]$ range for all policy values while imposing decreasing returns to hours worked: $\alpha=0.4$ and $\mu=0.95$. Employment shares for various degrees of flexibility and various taxation rates are presented in Figure 1. We pick $\rho=0.99$ to ensure taxation has an effect in terms of GDPs (for lower levels of $\rho$, with log-utility function, GDP per capita is negligibly affected by taxation). ${ }^{5}$ This ensures in addition that wages exhibit sufficient persistence and not too much downward movements, as is reported to be the case in the US and other countries (see, for instance, Schmieder and von Wachter (2009) and the references therein). The remaining 4 parameters are set so that we match 2 features of the wage distribution in the US: the ratio of the decile 9 to decile 5 wages, P9/5=2.34 (2.5 in the model), the ratio of decile 9 to decile 1 wage, $\mathrm{P} 9 / 1=4.89$ ( 5 in the model); we also match the ratio of part-time to full-time for men age 15-64 (8.23 in the US, 7.84 in the model); finally, we ask our benchmark economy to have a non-employment rate fitting between the average US unemployment rate $(6.4 \%)$ and the average non-employment rate $(21.06 \%)$ for men age 15 to 64 over the period 1983-2008. ${ }^{6}$ This leads our model to exhibit a non-employment rate of $13.6 \%$. Our model

\footnotetext{
${ }^{5}$ Section C.5 gives the intuition behind this.

${ }^{6}$ All data used in this section are either from the OECD statistical database or from the Groningen Growth and Development center. We use averages over the 1983-2008 period to reconcile data with the reality of our
} 
is one where agents cannot exit if unemployed for many periods, and in which, given the persistence, some workers remain non-employed for many periods. In real life, these persons would exit the work force. In some sense, these could be seen as building the ranks of the discouraged and marginal workers that the US Bureau of Labor Statistics includes in some of its measures of enlarged unemployment, although it is true discouraged workers do not tend to search actively (alternatives measures of the unemployment rate proposed by the BLS are discussed in Appendix A.2). We cannot be closer to the non-employment rate of men age 15-64, however, as with log-utility our model agents exhibit a great dislike of being non-employed. We choose to focus on men so as not to consider segments of the population for which the choice of part-time is too dependent on idiosyncrasies and personal preferences, but while keeping sufficient variance across countries. The numerical algorithm is described in Appendix B.

Table 1: Model Parameters

\begin{tabular}{lcc}
\hline \hline Parameter & Meaning & Value \\
\hline$\beta$ & discount factor & 0.99 \\
$\sigma$ & risk aversion & 1 \\
$\nu$ & labor/leisure parameter & 0.8 \\
$a$ & leisure scale coefficient & 0.5 \\
$\alpha$ & coefficient on firm type (production function) & 0.4 \\
$\mu$ & coefficient on hours (production function) & 0.95 \\
$\eta$ & Nash bargaining parameter & 0.7 \\
$\rho$ & persistence of shocks & 0.99 \\
$\epsilon$ & standard deviation of shocks & 0.2 \\
$\tau$ & income taxation rate & varies \\
$b$ & unemployment insurance & varies \\
$\pi$ & recontracting probability & varies \\
\hline \hline
\end{tabular}

In the next section, the effects of changes in the probability of recontracting and labor taxation are analyzed.

\subsection{Contracts, Taxes and Labor Market Performance}

The behavior of the model when the probability of recontracting changes, as well as when taxation varies, is examined. Sensitivity to changes in crucial parameters is discussed in steady-state economy, and start with 1983 as it is the year starting from which the Netherlands can be seen as having a less rigid labor market. 
details in Appendix C. The performance of the model in explaining cross-country differences with the help of differences in rigidity and income taxation is then evaluated in Section 4.3.

\subsubsection{What to Expect? A Look at Intuition}

In this economy, changes in parameters affect economic performance through a direct effect (all else equal) but also through changes in the quality composition of the pool of searchers. To make things more complicated, the quality composition of the pool depends on the number of searchers, and the effects may be different in situations with lots of searchers (high unemployment) or with little searchers. It is worthwhile trying to anticipate what will happen when flexibility and taxation levels change.

Starting with a fully flexible economy, in which unemployment is low, part-time is used by those pairs for which full-time employment is less attractive than search, but for which the expected future value is greater than the value of searching. Keeping the composition of the pool of searchers constant, a decrease in flexibility reduces the value of a part-time match, as there is a chance the pair cannot adapt its contract in the case of a positive productivity shock. Hence some employment and part-time will decrease. But the decrease in employment translates in an increase in the average quality of the pool of searchers. This has the effect of increasing the value of search, thus further decreases employment and part-time. The effect on part-time is not necessarily true at all levels of employment. Starting with an economy with high levels of rigidity, in which employment is small, and very good prospects are unmatched, an increase in flexibility logically has the opposite direct effect as the one anticipated for a decrease in rigidity: part-time work becomes more valuable and thus increased rigidity has a positive effect on part-time and employment. However in this economy, given the high quality of the pool, individuals are picky, and only the highest productivity pairs will accept the match, which will mostly be full-time. In addition, in the rigid economy, the only matched pairs are highly productive ones, a few of which may decide on part-time work. The rare part-time matches dissolve when hit by a positive shock whenever they cannot rebargain, a situation that happens a lot given the high level of rigidity. Hence overall the effect on parttime of increased flexibility, starting from a very rigid economy, is ambiguous. Given that employment increases unambiguously with flexibility, GDP per capita does so too. This is not the case, however, for GDP per hour. The effect of flexibility, as well as other parameters affecting hours worked, on GDP per hour depends on the composition of the pool of searchers. 
When employment is low, there are many relatively productive pairs looking for a match, increased employment will thus come with an increase in the average productivity. But when the economy is very flexible, it is much less probable that a high productivity match is made, and average productivity could decrease. An increase in taxation has a less ambiguous effect: it distorts the wage paid by the firm and received by the worker, and thus induces some full-time prospects to move to part-time, and some part-time prospects not to engage in a relationship. Hence, employment decreases (and thus GDP per capita), but the effect on part-time is not clear cut. Given the ambiguity of the effect of flexibility on GDP per hour and part-time, these changes can have different effects on part-time depending on the level of taxation in the economy.

\subsubsection{Effects of Flexibility in Contracting}

We expect flexibility to have an unambiguously positive effect on employment and GDP per capita, but we do not know ex-ante how it will affect part-time and GDP per hour. Figure 10 and Figure 11 in Appendix $\mathrm{C}$ confirm the unambiguity of the effects on most measures of performance we use. An increase in flexibility leads to an increase in GDP per capita, employment, total hours, and to a decrease in unemployment. Both total welfare and worker welfare increase, in addition, where we define total welfare as the sum of all individual utilities and all firm profits. Total profits increase as well. In theory, the effects are not as clear cut when looking at GDP per hour and at the share of part-time, as outlined above. The effect of flexibility on the share of part-time can be found in Table 2, as well as in the third panel of Figure 11. The share does start by decreasing, if very slightly when tax is zero. At some high level of flexibility, it increases once again. When the taxation is too high, however, the point of inflection is never reached, as taxation keeps employment at a lower level. The effect of flexibility on GDP per hour follows a similar logic. When employment is low, there are many relatively productive pairs looking for a match, increased employment will thus come with an increase in the average productivity. But when the economy is very flexible, it is much less probable that a high productivity match is made, and average productivity could decrease. This rarely happens in the simulation, as confirmed in Table 2. Effects of changes in flexibility are relatively robust to parameter changes, as can be seen in Appendix C. 
Table 2: Effects of flexibility

\begin{tabular}{c|c|cccc}
\hline \hline $\operatorname{tax}$ & $\pi$ & GDP per capita & GDP per hour & Unemployment & Part-time share \\
\hline 0.0 & & & & & \\
& 0.3 & 5.865 & 13.844 & 0.415 & 0.095 \\
& 0.7 & 7.610 & 14.440 & 0.238 & 0.075 \\
& 0.9 & 9.372 & 14.854 & 0.132 & 0.091 \\
\hline 0.3 & & & & & \\
& 0.3 & 5.843 & 13.952 & 0.418 & 0.123 \\
& 0.7 & 7.519 & 14.051 & 0.258 & 0.151 \\
& 0.9 & 9.307 & 15.060 & 0.132 & 0.153 \\
\hline 0.5 & & & & & \\
& 0.3 & 5.752 & 14.243 & 0.424 & 0.194 \\
& 0.7 & 7.477 & 15.076 & 0.324 & 0.185 \\
& 0.9 & 9.288 & 15.094 & 0.132 & 0.164 \\
\hline 0.7 & & & & & \\
& 0.3 & 5.572 & 15.110 & 0.464 & 0.247 \\
& 0.7 & 7.287 & 16.101 & 0.348 & 0.222 \\
& 0.9 & 8.800 & 15.952 & 0.213 & 0.197 \\
\hline \hline
\end{tabular}

\subsubsection{Effects of Labor Income Taxation}

As documented in Section 2, labor income taxation varies across countries. In general, the level of income taxation is much lower in the US than in Europe. From a theoretic perspective, income taxation distorts the marginal revenue of an extra hour of work. Hence, when the tax rate increases, workers wish to work less for a given wage. It will thus induce more pairs to work part-time. It may also push some low productivity pairs, already engaged in part-time, to unemployment. Can this be seen in our model? Table 3 displays the usual indicators of economic performance at different tax rates for two levels of flexibility. In the very flexible economy $(\pi=0.9)$, all the action is to be found in the share of part-time when moving from low to moderate taxation. Above a certain taxation rate, however, unemployment starts increasing. In an economy with lower levels of flexibility, the effect on unemployment starts directly when increasing the tax rate. Effects on other variables are clear cut (and expected). Increasing the tax rate has a positive effect on GDP per hour, and a negative one on GDP per capita, employment, total hours, welfare and profits.

\subsubsection{Effects of Changes in Other Parameters}

As mentioned before, changes in parameters have a small impact on the effects of changes in flexibility and taxation. They do have somme interesting effects of there own. For instance, 
Table 3: Effects of labor income taxation

\begin{tabular}{l|c|cccc}
\hline \hline$\pi$ & tax & GDP per capita & GDP per hour & Unemployment & Part-time share \\
\hline 0.3 & & & & & \\
& 0.0 & 5.865 & 13.844 & 0.415 & 0.095 \\
& 0.3 & 5.843 & 13.952 & 0.418 & 0.123 \\
& 0.5 & 5.752 & 14.243 & 0.424 & 0.194 \\
& 0.7 & 5.572 & 15.111 & 0.464 & 0.247 \\
\hline 0.9 & & & & & \\
& 0.0 & 9.372 & 14.854 & 0.132 & 0.092 \\
& 0.3 & 9.307 & 15.060 & 0.132 & 0.151 \\
& 0.5 & 9.288 & 15.094 & 0.132 & 0.164 \\
& 0.7 & 8.800 & 15.952 & 0.213 & 0.197 \\
\hline \hline
\end{tabular}

an increase in risk aversion induces workers to be less picky and match with lower firm types. This results in higher employment, higher GDP per capita, lower GDP per hour, and a greater share of part-time jobs. Lowering the persistence of the shocks leads to less sorting in equilibrium, since current productivity is less informative about future productivity, making the future value of being in a match closer to the value of searching. Increasing the bargaining power of the workers leads to a higher share of part-time jobs and a lower unemployment rate. The effects on GDP per capita and GDP per hour depend on flexibility, however. In an economy with a high degree of flexibility, more power to the workers leads to a lower GDP per capita but a higher GDP per worker, the reverse being true in a rigid economy.

Unemployment insurance has either very little effects or enormous ones, depending on whether the insurance payment is sufficiently smaller than the minimum wage in the economy or not. Unemployment insurance has no direct effects on part-time work, as it is perceived only by unemployed workers. However, it does increase the part-time share slightly, especially when flexibility is high, as it increases the outside option of workers in the bargaining.

Tables illustrating the effects of changes in these parameters in more details, as well as effects of changes in the remaining parameters, are presented in Appendix C.

\subsection{Can the Model Explain Cross-country Differences?}

It is now time to test the model against the data. In our parametrization, we have tried to fit the model closely to the US, where we assumed the US to be a very flexible country with bargaining rigidity $\pi=0.9$ and taxation level of $\tau=0.3$. Given implied taxation rates provided in Table 9 in the Appendix, which we recall in the second column of Table 4, our 
objective is now to find the levels of flexibility $\pi$ that allow us to come closest to GDP per capita relative to the US in a subset of OECD countries. ${ }^{7}$ We then check the performance of our model by looking at how well it explains differences in GDP per hour, unemployment, and the share of part-time. The results can be found in Tables 4 and 5. Finally, we test the relative importance of income taxation and rigidities by performing to counterfactual experiments. In the first, we shut down the rigidity channel and assume countries only differ in income taxation (Table 6). In the second, we assume all countries have the same income taxation level, but they differ in their level of rigidity (Table 7).

Table 4 shows the GDP per capita and income tax rates for our subset of countries, the GDP per capita obtained in our model, the income tax rate assumed, and the implied flexibility parameter $\pi$. To obtain the correct GDP per capita in our model, given taxation rates, we find that it is necessary to assume that Spain and Italy have similarly high labor market rigidities, that France is just slightly more flexible, that Germany is more flexible than France and, in turn, Belgium, the UK and especially the Netherlands are the countries coming closet to US flexibility. From our reading of the data, summarized in Section 2 and detailed in the Appendix, the model is able to predict well the level of flexibility in each country. Can it do better than that?

Table 4: GDP per capita, taxation, in real life and in the model, and implied flexibility

\begin{tabular}{ll|c|c|c|c}
\hline \hline Countries & GDP pc & Income Taxation & Model GDP pc & Model income tax rate & Implied $\pi$ \\
\hline Belgium & 80 & 48.2 & 79.6 & 0.5 & 0.7 \\
France & 73 & 47.2 & 69.9 & 0.5 & 0.5 \\
Germany & 76 & 41.4 & 74.7 & 0.4 & 0.6 \\
Italy & 67 & 47.3 & 65.2 & 0.5 & 0.4 \\
Netherlands & 87 & 50.5 & 87.1 & 0.5 & 0.8 \\
Spain & 65 & 37.8 & 65.2 & 0.4 & 0.4 \\
UK & 79 & 23.7 & 81.7 & 0.2 & 0.7 \\
US & 100 & 26.7 & 100 & 0.3 & 0.9 \\
\hline \hline
\end{tabular}

Notes: the data of GDP per capita for 2008 are from the Groningen Growth Data Center; the income tax data are the average of effective tax rates under the period 1991-1997 updates through 1997 calculated using the method proposed in Mendoza, Razin, and Tesar (1994).

In Table 5, we contrast our model predictions to the data using our usual indicators, GDP

\footnotetext{
${ }^{7}$ We focus on GDP per capita as it is the most widely used indicator of economic performance, it is not affected by measurement issues, and our objective is to see how much our parameter $\pi$ can explain of the cross country differences in hours, employment, non-employment, and unemployment, share of part-time, and GDP per hour.
} 
per capita, GDP per hour, non-employment, and share of part-time. We also present data on unemployment, as the way we model non-employment is to be interpreted as something of a mix between unemployment and non-employment. It is worthwhile remembering that the good fit of GDP per capita is by construction, as is the good fit between our model US economy and the data. Clearly, the model is able to replicate well the data on GDP per hour for all countries but Spain (and to a lower extent, Italy). The model predicts higher productivity levels than can be observed in that country. This is not surprising, as the dismal spanish productivity level constitutes a well documented puzzle. Lowering the risk aversion parameter for the simulation of spanish data would help, but we think other explanations of the low spanish productivity (institutions (Gual, Jodar-Rosell, and Ruiz, 2006), use of temporary labor contracts (Aguirregabiria and Alonso-Borrego, 2009), structure of the work day (Danthine and Lalive, 2009)) are more promising but not in the scope of our model.

Workers in our model can only be employed or non-employed, and some may remain unemployed for very long spells (more than 25 periods). In real life, these persons would have left the labor force. In real-life, however, not all non-employed search for a job, although surveys compute that anywhere from 1 to 5 percent of persons out of the labor force would take a job if it presented itself. In all fairness, we also present the average unemployment rate over the same period, 1983-2008, and the present day unemployment rate (first quarter of 2009), which clearly are those of economies in deep crisis. ${ }^{8}$ It should be emphasized that we only look at the data for men of working age.

The model is able to reproduce well the non-employment/population ratios in this sample of OECD countries. While it overshoots some of the countries, like Germany, and especially Spain, or Italy, it does so in limited fashion. It also undershoots other countries, like Belgium or France. The model's performance is less impressive when asked to reproduce the levels of unemployment within men in working age. While the non-employed in our model are all searchers, some of them have been searchers so long they wouldn't be counted as unemployed in official data. In some sense, we include in the model measure of non-employment, all unemployed workers, all discouraged workers, and some more marginal members of the labor force or of the out-of-labor force. ${ }^{9}$ From this point of view, our model predicts much larger

\footnotetext{
${ }^{8}$ We use data from the U.S. Bureau of Labor Statistics here as they provide the latest unemployment rate for the set of countries we are interested in while the OECD data stop in 2008.

${ }^{9}$ The Bureau of Labor Statistics does not count discouraged workers as unemployed but rather refers to them as only "marginally attached to the labor force", and has developed six alternative measures of labor
} 
Table 5: Economic performance in real life and in the model

\begin{tabular}{l|cccccccc}
\hline \hline Countries & \multicolumn{2}{|c}{ GDP pc } & \multicolumn{2}{c}{ GDP ph } & \multicolumn{2}{c}{ NEPr } & \multicolumn{2}{c}{ PT } \\
& Data & Calibrated & Data & Calibrated & Data & Calibrated & Data & Calibrated \\
\hline Belgium & 80 & 79.5 & 99 & 97.2 & 32.24 & 30.9 & 5.11 & 2.5 \\
France & 73 & 69.7 & 95 & 92.6 & 31.24 & 34.1 & 5.07 & 2.2 \\
Germany & 76 & 74.5 & 92 & 92.3 & 25.89 & 31.4 & 3.74 & 4.4 \\
Italy & 67 & 65.1 & 83 & 89.5 & 30.83 & 39.2 & 4.63 & 3.1 \\
Netherlands & 87 & 86.9 & 101 & 99.1 & 23.37 & 25.7 & 14.47 & 9.2 \\
Spain & 65 & 65.1 & 74 & 89.5 & 29.49 & 39.2 & 2.51 & 3.1 \\
UK & 79 & 81.6 & 89 & 91.3 & 21.63 & 25.4 & 6.61 & 5.2 \\
US & 100 & 100 & 100 & 100 & 21.06 & 13.6 & 8.1 & 7.8 \\
\hline \hline
\end{tabular}

Unemployment, Data

\begin{tabular}{l|cc} 
Countries & Ur & Ur BLS \\
\hline Belgium & 6.67 & 8.9 \\
France & 8.41 & 7.2 \\
Germany & 7.46 & 7.7 \\
Italy & 7.59 & 8.0 \\
Netherlands & 5.59 & 3.1 \\
Spain & 13.33 & 16.5 \\
UK & 7.92 & 7.0 \\
US & 6.06 & 8.1 \\
\hline \hline
\end{tabular}

Notes: GDP per capita and GDP per hour are from the Groningen Growth Data Center for 2008. NEPr corresponds to the average non-employment/population ratio for men between age 15-64 from 1983 to 2008; PTs corresponds to the average parttime share for men between age 15-64 from 1983 to 2008 and Ur corresponds to the unemployment rate of men between age 15-64 from 1983 to 2008. These three data are from the OECD Statistical database. Ur BLS corresponds to the unemployment rates adjusted to U.S. concepts by the Bureau of Labor Statistics for the first Quarter of 2009. 
levels of discouraged workers in countries with high rigidities than in countries with low ones, a feature consistent with the data. Regarding the share of part-time, the model fares relatively well once more. It underpredicts part-time share in Belgium, France, and the Netherlands, but it tends to rank the countries well. Clearly, when trying to explain economic performance, flexibility and income taxation are not the end of the story, but a large part of it.

The model does a good job replicating the data using two key parameters, flexibility and labor income taxation parameters $(\pi$ and $\tau$ ). Could it do so using just one of these parameters? To answer this, we propose two counterfactual experiments in Tables 6 and 7 . The first counterfactual assumes all countries have the same level of flexibility, thus isolating the effect of income taxation in our model. Conversely, the second counterfactual assumes identical income taxation across countries, but lets flexibility vary to the levels implied at the beginning of this section.

Table 6: Counterfactual: Taxation rates vary

\begin{tabular}{l|cccccc}
\hline \hline Countries & $\pi$ & Taxation & GDP pc & GDP ph & NEPr & PT \\
\hline Belgium & 0.9 & 0.5 & 99.6 & 100.23 & 15.7 & 9.6 \\
France & 0.9 & 0.5 & 99.6 & 100.23 & 15.7 & 9.6 \\
Germany & 0.9 & 0.4 & 99.92 & 100.07 & 14.4 & 8.4 \\
Italy & 0.9 & 0.5 & 99.6 & 100.23 & 15.7 & 9.6 \\
Netherlands & 0.9 & 0.5 & 99.6 & 100.23 & 15.7 & 9.6 \\
Spain & 0.9 & 0.4 & 99.92 & 100.07 & 14.4 & 8.4 \\
UK & 0.9 & 0.2 & 100.41 & 99.19 & 13.1 & 7.1 \\
US & 0.9 & 0.3 & 100 & 100 & 13.6 & 7.8 \\
\hline \hline
\end{tabular}

There are four groups of countries in our sample in terms of taxation: the US and the UK each constitute their own group, with taxation at 0.3 and 0.2 respectively. Continental Europe is then divided in two groups, with Belgium, France, Italy, and the Netherlands all taxing at 0.5 , and Germany and Spain taxing at 0.4. The outcome of our first counterfactual is then to predict a big divide between high taxation continental Europe and low taxation anglo-saxon countries the US. Taxation alone cannot properly account for differences within continental Europe. Neither can it explain why the UK has a both a smaller production level per capita and a smaller productivity level than the US. In addition, given the way

underutilization (see Appendix A.2 for details). In October 2009, for instance, the official unemployment rate was reported to be $10.2 \%$, the broadest measure of unemployment and underutilization was $17.5 \%$, and the measure that most corresponds to our unemployment in the model (U-5) was $11.6 \%$. 
taxation is introduced in the model, differences across countries are small and it is impossible to explain the magnitude of the variation in economic performance. Turning to our second counterfactual table, assuming all countries adopt the US tax code, but vary in terms of rigidity, the model is able to replicate relatively well the GDP per capita of these countries (but keep in mind that the rigidity parameter was chosen to match this perfectly at the real taxation levels), but it performs worse in terms of productivity, non-employment and parttime share. To sum up, rigidity is the crucial parameter that allows the model to perform well with regards to GDP per capita and GDP per hour. Taxation is important, however, to help explain differences in non-employment and part-time share, but it cannot do this without rigidities. The interaction between these two ingredients is necessary for our model to reproduce well qualitatively and quantitatively the patterns of GDP per capita, GDP per hour, unemployment (or non-employment) and part time jobs in a large set of countries, Spain being an exception. Rigidities and labor income taxation prove therefore to be empirically relevant to explain the differences in economic performance across countries.

Table 7: Counterfactual: rigidity varies

\begin{tabular}{l|cccccc}
\hline \hline Countries & $\pi$ & Taxation & GDP pc & GDP ph & NEPr & PT \\
\hline Belgium & 0.7 & 0.3 & 81.6 & 95.81 & 27.36 & 4.0 \\
France & 0.5 & 0.3 & 70.42 & 93.01 & 34.64 & 3.52 \\
Germany & 0.6 & 0.3 & 76.21 & 93.98 & 31.14 & 3.7 \\
Italy & 0.4 & 0.3 & 65.7 & 91.86 & 37.17 & 3.4 \\
Netherlands & 0.8 & 0.3 & 90.24 & 99.98 & 22.29 & 6.1 \\
Spain & 0.4 & 0.3 & 65.7 & 91.86 & 37.17 & 3.4 \\
UK & 0.7 & 0.3 & 81.6 & 95.81 & 27.36 & 4.0 \\
US & 0.9 & 0.3 & 100 & 100 & 13.6 & 7.8 \\
\hline \hline
\end{tabular}

\section{Conclusion}

This paper focuses on the impact of rigidity in contracting and labor income taxation on economic performance in a subset of OECD countries. It shows that these labor market features are of first order importance in explaining differences in GDP per capita, GDP per hour, non-employment and the proportion of part-time jobs amongst European countries, as well as between European countries and the US. To do so the analysis is conducted in a matching model in which risk-averse workers and risk-neutral firms vary in productivity 
and face idiosyncratic shocks to productivity. Four elements of the model are necessary to explain the observed cross-country differences: bargaining over the length of the workday, heterogeneity, contracting frictions and income taxes. While labor income taxation alone is not enough to account for cross-country differences in economic performance including the proportion of part-time jobs, the interaction of variations in bargaining rigidities on both wages and hours with differences in income taxation goes a long way in explaining differences in economic performance both qualitatively and quantitatively.

\section{References}

Aguirregabiria, V., and C. Alonso-Borrego (2009): "Labor Contracts and Flexibility: Evidence from a Labor Market Reform in Spain," Working Papers tecipa-346, University of Toronto, Department of Economics.

Blazquez, M., And M. Jansen (2008): "Search, mismatch and unemployment," European Economic Review, 52(3), 498-526.

Botero, J., S. Djankov, R. LaPorta, and F. C. Lopez-De-Silanes (2004): "The Regulation of Labor," Quarterly Journal of Economics, 119(4), 1339-1382.

Bureau of Labor Statistics (2009): "Table A-12. Alternative Measures of Labor Underutilization," http://www.bls.gov/news.release/empsit.t12.htm.

Calvo, G. A. (1983): "Staggered prices in a utility-maximizing framework," Journal of Monetary Economics, 12(3), 383-398.

Danthine, S. (2005): "Two-Sided Search, Heterogeneity and Labor Market Performance," Discussion Paper 1572, IZA.

Danthine, S., And R. Lalive (2009): "A Siesta a day may actually pay," University of Lausanne.

DÉlÉgation du SÉnAt pour L’Union Européenne (1998): “Quelles Politiques de l'Emploi pour la Zone Euro," Rapport d'Information 388.

Gertler, M., and A. Trigari (2009): "Unemployment Fluctuations with Staggered Nash Wage Bargaining," Journal of Political Economy, 117(1), 38-86. 
Gual, J., S. Jodar-Rosell, and A. Ruiz (2006): "The Role of Regulation in the Spanish Productivity Problem (El problema de la productividad en Espaa: cul es el papel de la regulacin?)," SSRN eLibrary.

Hu, Y., And K. Tijdens (2003): "Choices for part-time jobs and the impacts on the wage differentials. A comparative study for Great Britain and the Netherlands," IRISS Working Paper Series 2003-05, IRISS at CEPS/INSTEAD.

Ljungqvist, L., And T. J. SARgent (2007): "Do Taxes Explain European Employment? Indivisible Labour, Human Capital, Lotteries and Savings," in NBER Macroeconomics Annual 2006, vol. 21, pp. 181-246. NBER.

McCann, D. (2005): Working Time Laws: A global perspective. Findings from the ILO's Conditions of Work and Employment Database. International Labour Organization.

Mendoza, E. G., A. Razin, and L. L. Tesar (1994): "Effective Tax Rates in Macroeconomics: Cross-Country Estimates on Factor Income and Consumption," Journal of Monetary Economics, 34(3), 297-323.

NAGYPÁL, E. (2005): "On the extent of job-to-job transition," Northwestern University.

Nickell, S. (2004): "Employment and Taxes," CEP Discussion Papers 0634, Centre for Economic Performance, LSE.

Nickell, S., AND J. VAN OuRs (2000): "The Netherlands and the United Kingdom: a European Unemployment Miracle?," Economic Policy, 15(30), 135-180.

OECD (2004): OECD Employment Outlook 2004. OECD.

Ortega, J. (2003): "Working-Time Regulation, Firm Heterogeneity, and Efficiency," CEPR Discussion Papers 3736, Center for Economic Policy Research.

Pissarides, C., P. Garibaldi, C. Olivetti, B. Petrongolo, and E. Wasmer (2005): "Women in the labor force: How well is Europe doing?," in European Women at Work, ed. by T. Boeri, D. del Boca, and C. Pissarides, pp. 1-56. Oxford University Press.

Pissarides, C. A. (2007): "Unemployment and Hours of Work: The North Atlantic Divide Revisited," International Economic Review, 48(1), 1-36. 
(2009): "The Unemployment Volatility Puzzle: is Wage Stickiness the Answer?," Econometrica, 77(5), 1339-1369.

Prescott, E. C. (2003): "Why Do Americans Work So Much More Than Europeans?," Staff Report 321, Federal Reserve Bank of Minneapolis.

Rogerson, R. (2006): "Understanding Differences in Hours Worked," Review of Economic Dynamics, 9(3), 365-409.

Schmieder, J., and T. von Wachter (2009): "Does Wage Persistence Matter for Employment Fluctuations? Evidence from Displaced Workers," Columbia University.

Tauchen, G. (1986): "Finite State Markov Chain Approximations to Univariate and Vector Autoregrations," Economic Letters, 20(2), 177-181.

World Bank (2006): Doing Business 2006. World Bank. 


\section{Appendices}

\section{A More on Economic Performance and Labor Market Insti- tutions: Levels and Trends}

In this appendix, more details about economic performance and labor market institutions for Belgium, France, Germany, the Netherlands, Spain, Italy, the UK and the US are provided.

\section{A.1 Economic Performance}

GDP per capita, GDP per hour and GDP per worker for the period 1970 to 2008 for Belgium, France, Germany, the Netherlands, Spain, Italy, the UK and the US are displayed in Figure 2. The employment/population ratio, the unemployment rate and the labor force participation are depicted in Figure 3. ${ }^{10}$ Total annual hours, annual hours per capita and annual hours per worker can be found in Figure $4 .{ }^{11}$ The US had a higher GDP per capita over the whole period, and the gap has even increased recently. The unemployment rate was lower in European countries than in the US during the seventies, but increased in these countries during the eighties, while remaining constant in the US. It is worth noting that, since the nineties, the UK and the Netherlands are the only countries able to match the US in terms of low unemployment rates. Observe in addition that the employment/population ratio has decreased during the 70's in most European countries while it increased across time in the US. Since the eighties, while France's employment rate remained constant, the employment rate of the Netherlands and the UK went on an upward trend and got back to the level of the employment rate in the US. ${ }^{12}$ The employment rate of Germany exhibits a positive trend since the eighties and is now close to the American one while the employment rate of Belgium, Italy and Spain has increased to reach a rate close to the one of France. Looking at Labor force participation, one notices that all countries exhibit an upward trend in the seventies. This trend grows stronger in the Netherlands after 1987 and in Germany during the nineties such that this rate is nowadays close to the one of the UK and the US. This trend

\footnotetext{
${ }^{10}$ Data for Belgium and the UK are available only from 1983.

${ }^{11}$ All data used here are from the OECD statistical database (employment/population rate, unemployment rate and labor force participation rate) and from the Groningen Growth and Development Center (GDP per capita, GDP per hour, GDP per worker, total annual hours, annual hours per capita and annual hours per worker).

${ }^{12}$ The discreet jump in the employment rate and the labor force participation rate in the Netherlands in 1987 is due to a change of series.
} 
remains almost constant for France since the eighties but grows in Belgium, Italy, and grows even stronger in Spain. Looking at Figure 4, the US had more total hours than European countries in 1970, and while hours went on a downward trend in all European countries, they increased or remained relatively constant in the US.

Controlling for the population, hours per capita increased in the US while it decreased in Belgium, Germany, Italy and France. For instance, since 1970, people work $20 \%$ less hours in France and $20 \%$ more hours in the United States. In Spain, the Netherlands and the UK, hours per capita followed the French trend until the mid 1980's but then started increasing again until recently. Controlling for workers, the situation is relatively stationary in the US while hours worked per employee are decreasing in all European countries. The evolution of employment and hours over the period at hand results in an increase in GDP per hour in most European countries relative to the US, except in the UK where this trend remains relatively constant. In the most recent years, however, European countries have seen a reduction in its level of GDP per hour relative to the US.

The change in economic performance in the early 1980's in the Netherlands and in the UK can be attributed to increased flexibility in the labor market, and most notably an increased flexibility regarding part-time work in the Netherlands. ${ }^{13}$ The evolution of the proportion of part-time jobs over time is instructive, as can be noted by looking at Figure 5. Over the last twenty years the Netherlands always had the greatest proportion of part-time work in the whole population. ${ }^{14}$ In the other countries, part-time employment is less prevalent. However, the number of part time jobs is relatively high in the UK and has increased quite strongly in Belgium and Germany across time while it remained lower and constant in France and the US. The number of these part time jobs has also increased in Italy and Spain but is still very low.

The proportion of part-time jobs has increased a lot among the whole population in the Netherlands. It has also increased significantly in Belgium and Germany, if less than in the Netherlands. It has remained constant, but at a relatively high level in the UK. This is mostly explained by the fact that part-time work is very prevalent for women in those

\footnotetext{
${ }^{13}$ Part-time jobs are defined by the OECD as jobs for which the individuals work less than 30 hours a week.

${ }^{14}$ To a large extent, part-time work is chosen in accordance with the preferences of workers. For instance, $78 \%$ of working part-time women in the Netherlands do not want to work full-time (see Nickell and van Ours (2000)). In addition, there is evidence that a fraction of part-time in the Netherlands is of the retention type (See Hu and Tijdens (2003)).
} 
Figure 2: Economic Performance - GDP
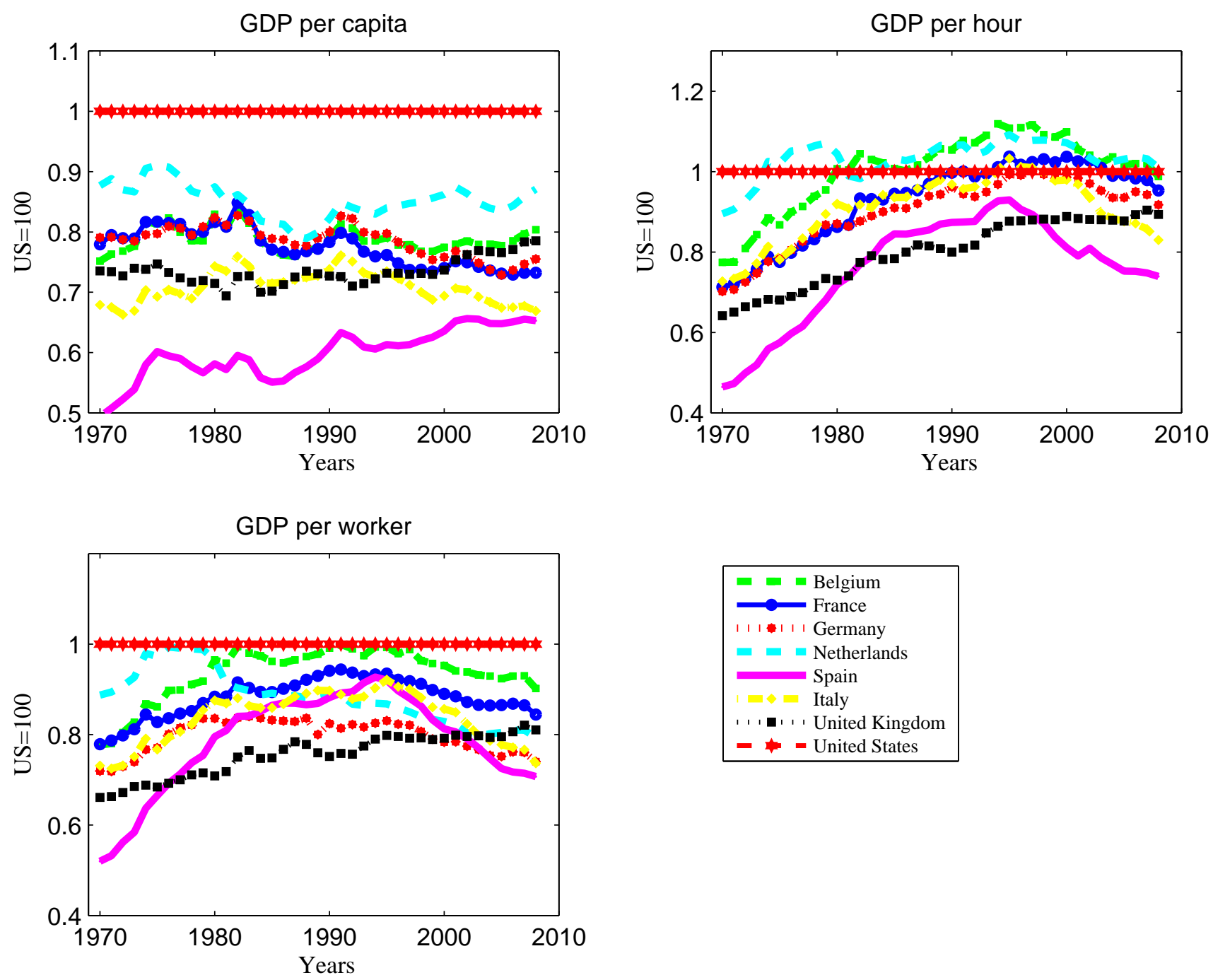

$$
\begin{aligned}
& \text { - }- \text { Belgium } \\
& \text { France } \\
& \text { । । । 1 । I Germany } \\
& \text { - } \square \text { Netherlands } \\
& \text { Spain } \\
& \text { Italy } \\
& \text { ' , । I , United Kingdom } \\
& \text { - - United States }
\end{aligned}
$$

Source: Groningen Growth and Development Center. 
Figure 3: Economic Performance - Employment/Unemployment
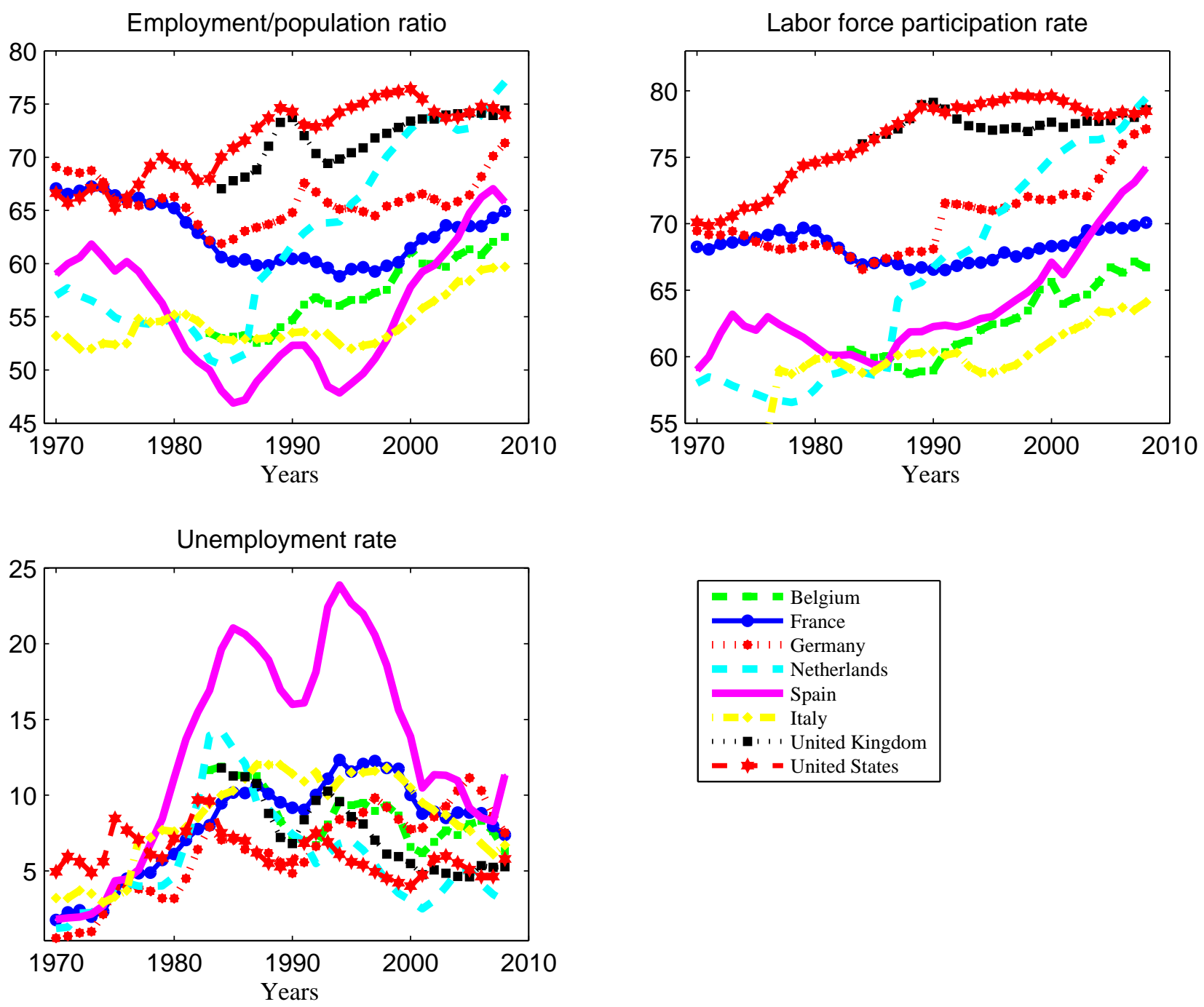

$$
\begin{aligned}
& \text { - }- \text { Belgium } \\
& \text { France } \\
& \text { । । । । । Germany } \\
& \text { - Netherlands } \\
& \text { Spain } \\
& \text { 1 1 1 - , United Kingdom } \\
& \text { - - United States }
\end{aligned}
$$

Source: OECD Statistical database. 
Figure 4: Hours worked per worker and per capita
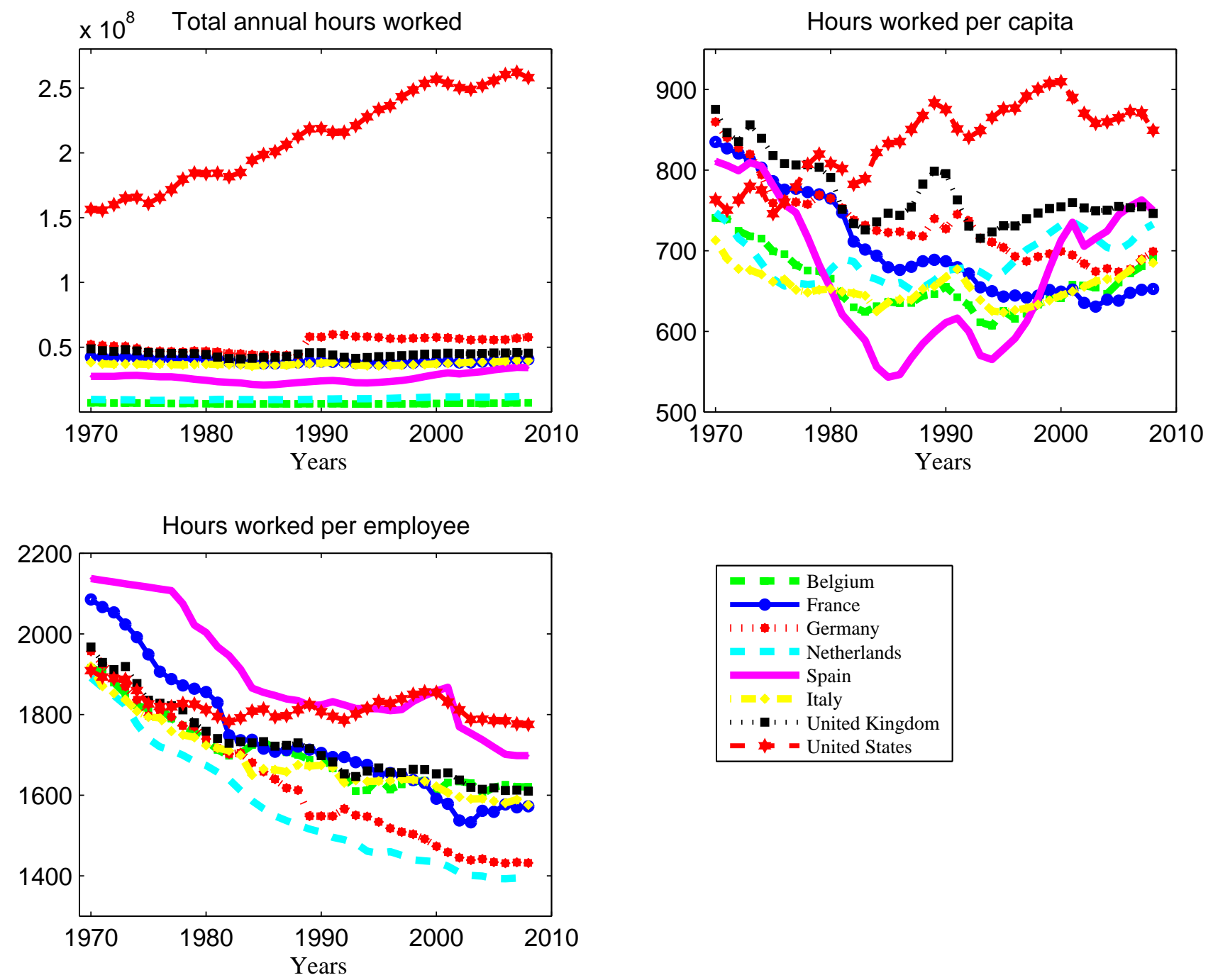

Notes: Hours per capita = Total Annual Hours Worked (in thousands) / Midyear population (in thousands of persons), Hours per employee = Total Annual Hours Worked (in thousands)/Persons engaged (in thousands of persons) Source: Groningen Growth and Development Center. 
countries (see Figures 5 and 8). ${ }^{15}$ The importance of part-time work among women is true for other countries as well. ${ }^{16}$ Looking at the distribution of part time jobs by age, there is little change in part-time employment for the different age groups within the whole population (see Figure 6). The use of part-time work is highest in the 15-24 age category (see Figure 6). This does not come as a surprise since most working individuals in that age category will do so in parallel to pursuing a diploma. Partial work days are less prevalent in the 25-54 age category. This is even more the case if focusing on males of age 25-54 (see Figure 7). But even within this category, differences across countries are still striking. Finally, the proportion of part-time jobs is greater again in the population of age 55 and more. ${ }^{17}$

\section{A.2 Measuring Unemployment}

In the US, the Bureau of Labor Statistics does not count discouraged workers as unemployed but rather refers to them as only "marginally attached to the labor force" (see Bureau of Labor Statistics (2009)). This has led some economists to believe that the actual unemployment rate in the United States is higher than what is officially reported while others suggest that discouraged workers voluntarily choose not to work. Nonetheless, the U.S. Bureau of Labor Statistics has developed and publishes alternative measures of labor underutilization from the unpublished Current Population Survey data. The six measures are:

- U-1, persons unemployed 15 weeks or longer, as a percent of the civilian labor force (5.7\% in October 2009);

- U-2, job losers and persons who completed temporary jobs, as a percent of the civilian labor force $(6.9 \%$ in October 2009$)$;

- U-3, total unemployed, as a percent of the civilian labor force (this is the definition used for the official unemployment rate) (10.2\% in October 2009);

- U-4, total unemployed plus discouraged workers, as a percent of the civilian labor force plus discouraged workers (10.7\% in October 2009);

\footnotetext{
${ }^{15}$ See Pissarides, Garibaldi, Olivetti, Petrongolo, and Wasmer (2005) for more on this topic.

${ }^{16}$ Looking across gender, one observes that the proportion of women employed part-time is higher than the proportion of men.

${ }^{17}$ In most European countries, women of age 55 and more account for most of women part-time, with women in the 15-24 age category coming a close second.
} 
Figure 5: All part-time jobs
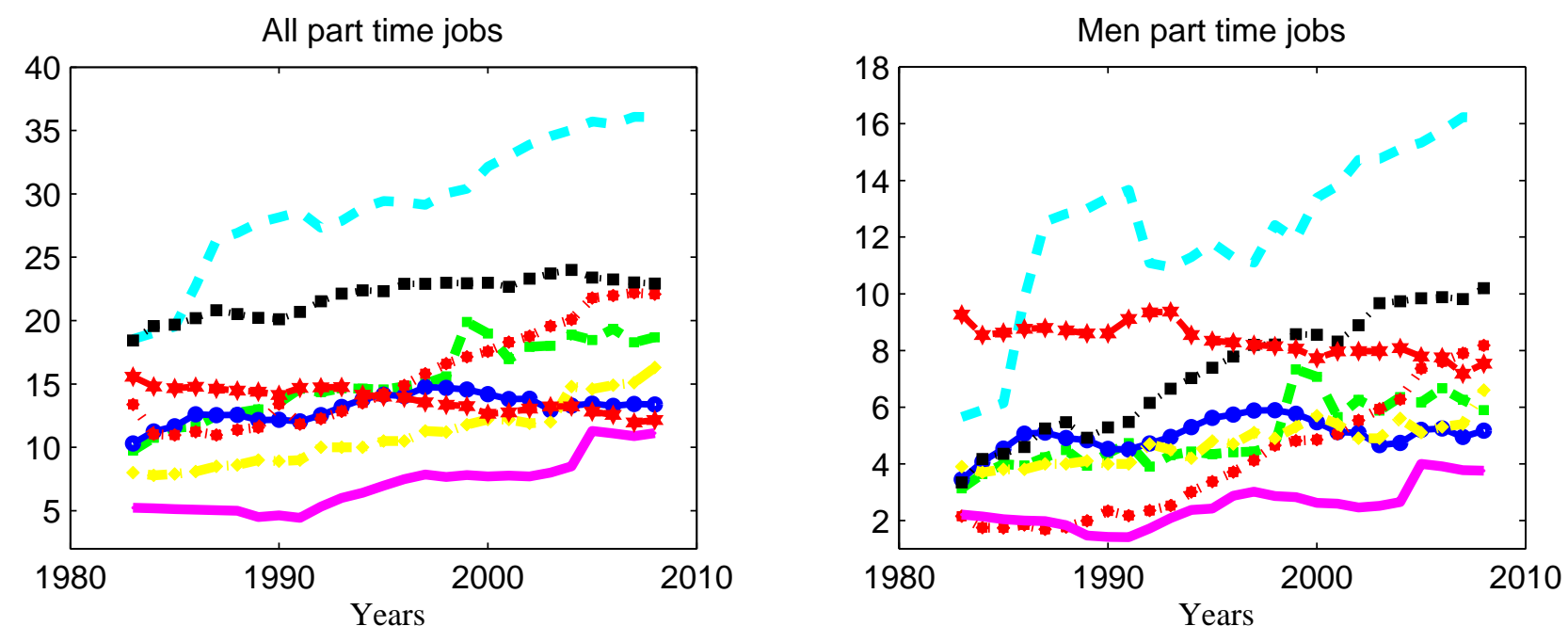

Women part time jobs

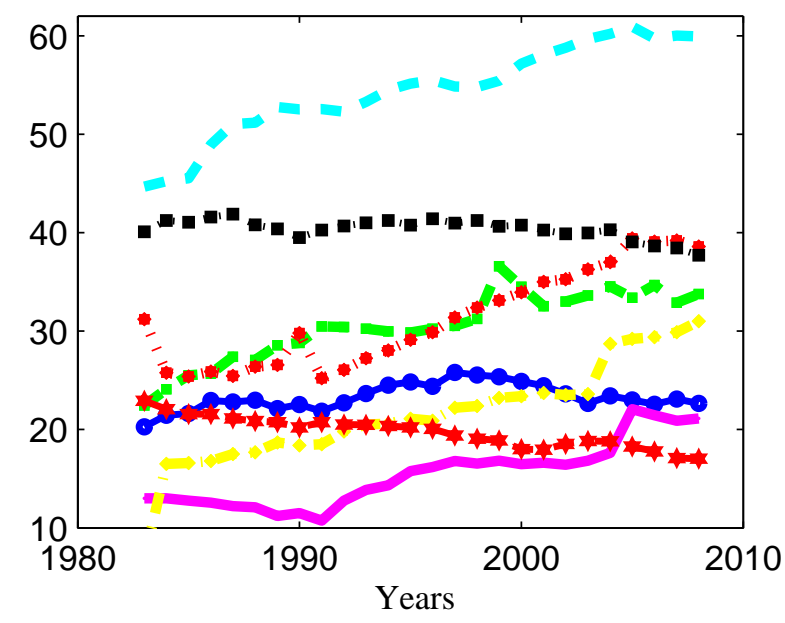


Figure 6: Distribution of part-time jobs across ages
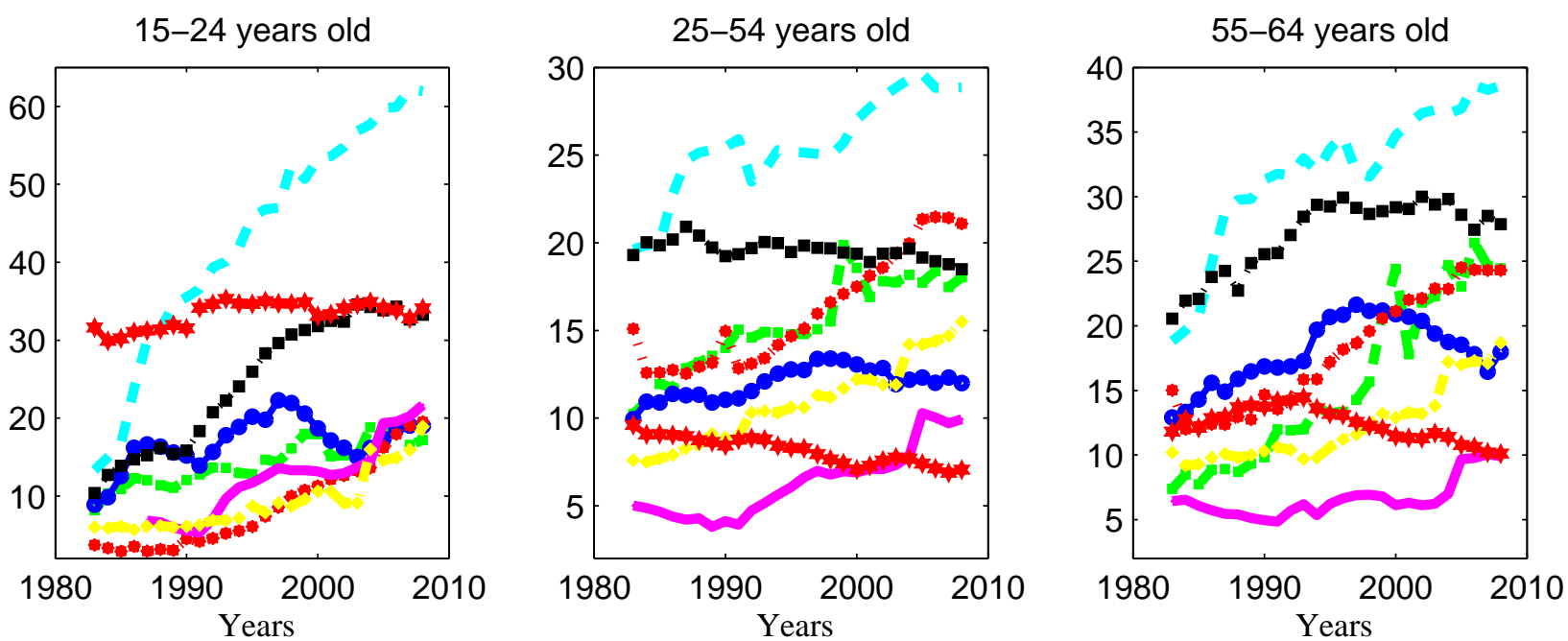

+65 years old

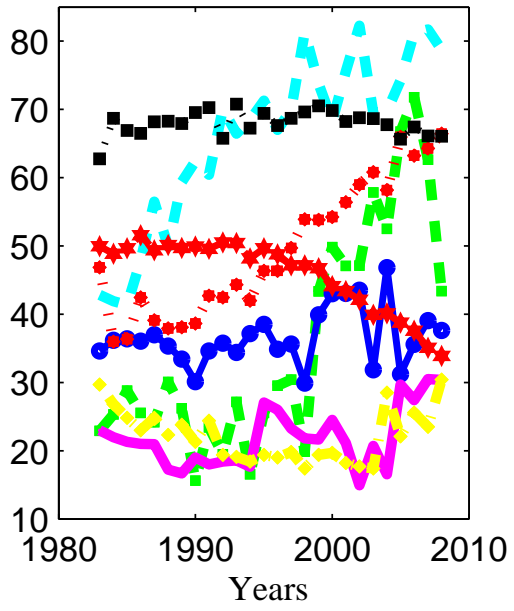

- $\square$ Belgium

France

। । । I । Germany

- Netherlands

Spain

$\downarrow-0 \otimes-$ Italy

, , 1 1 , , United Kingdom

- - United States 
Figure 7: Men part-time jobs
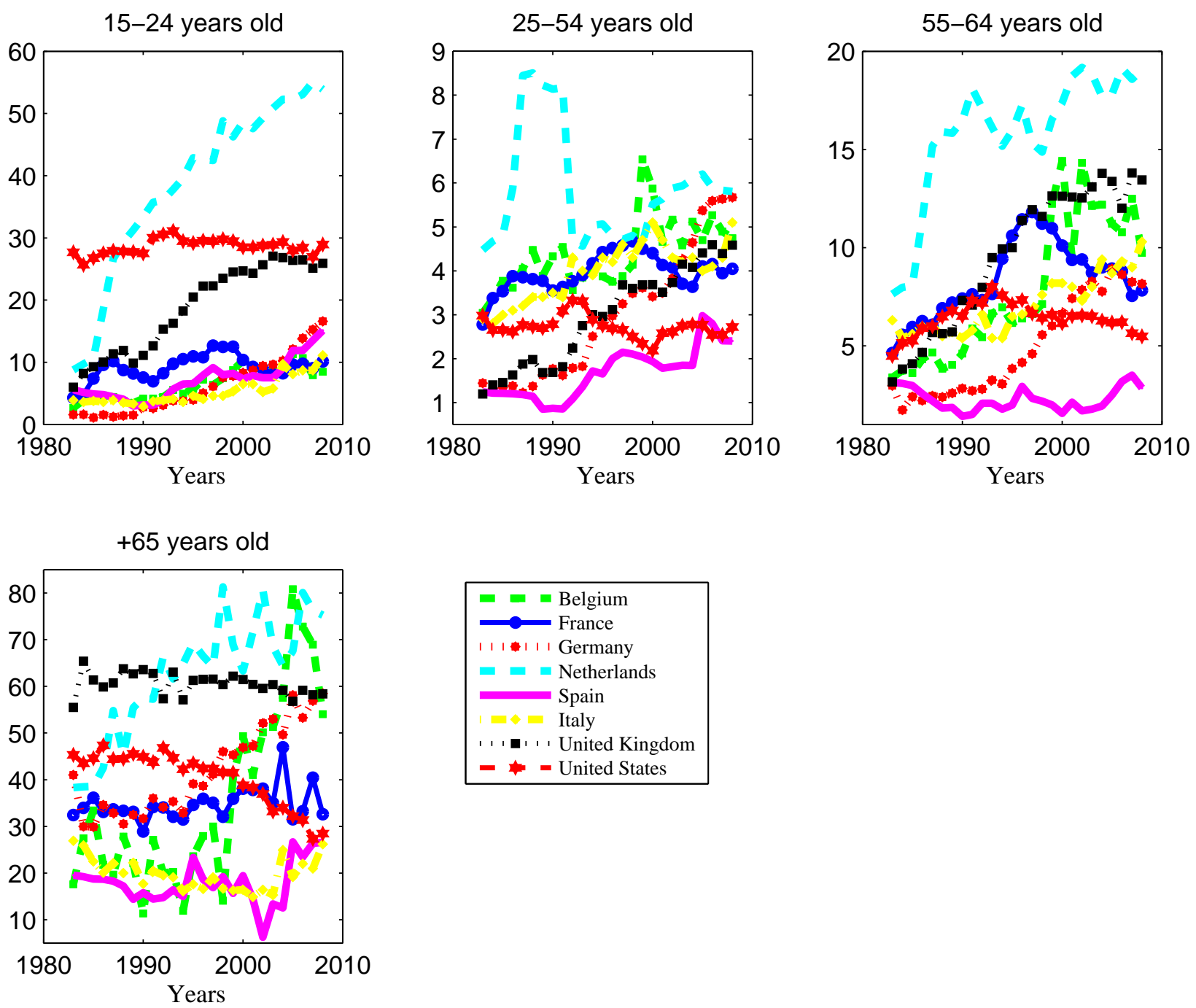

$$
\begin{aligned}
& \text { - }- \text { Belgium } \\
& \text { France } \\
& \text { । 1 1. 1 । Germany } \\
& \text { - } \square \text { Netherlands } \\
& \begin{array}{ll}
- & \text { Spain } \\
\text { Italy }
\end{array} \\
& \text { 1 , 1 } 1 \text {, , United Kingdom } \\
& \text { - }+ \text { United States }
\end{aligned}
$$


Figure 8: Women part-time jobs
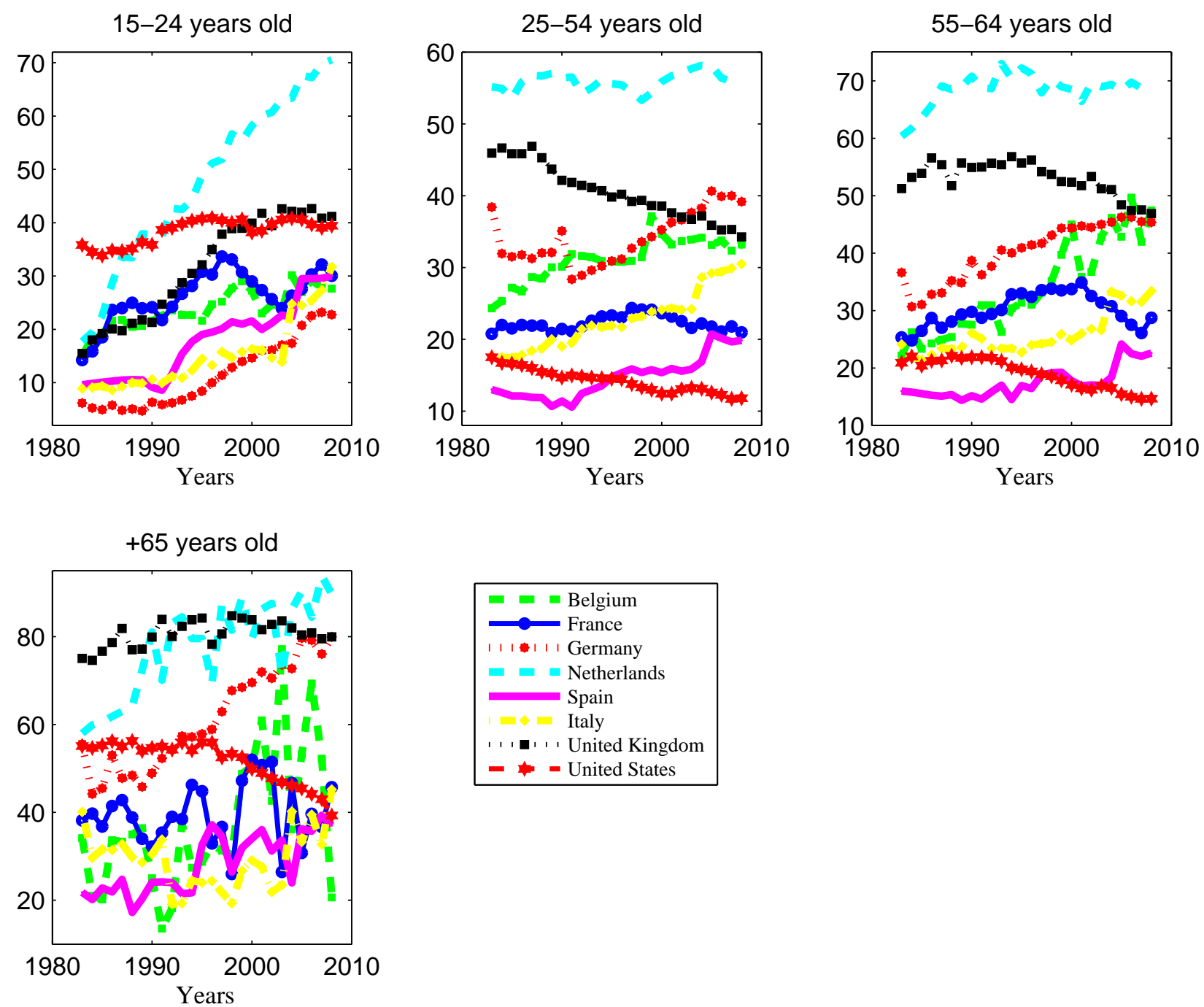

$$
\begin{aligned}
& \text { - }- \text { Belgium } \\
& \text { France } \\
& \text { । I । I I Germany } \\
& \square \square \text { Netherlands } \\
& \text { Spain } \\
& \downarrow-\theta=\text { Italy } \\
& \text { 1 । 1 } 1 \text {, , United Kingdom } \\
& \text { - }+ \text { United States }
\end{aligned}
$$


- U-5, total unemployed, plus discouraged workers, plus all other marginally attached workers, as a percent of the civilian labor force plus all marginally attached workers (11.6\% in October 2009); and

- U-6, total unemployed, plus all marginally attached workers, plus total employed part time for economic reasons, as a percent of the civilian labor force plus all marginally attached workers (17.5\% in October 2009).

Most news organizations report the more popular U.S. Department of Labor measure, Civilian Unemployment Rate, but recently there have been mentions of the broader measures in the US press. Recently, while unemployment was reported at $10.2 \%$ for October 2009, the broadest measure of unemployment and underemployment, U-6, was $17.5 \%$, with other measure ranging in between. Unfortunately we are not able to use these measures as the BLS does not prepare international comparisons on the U-1 to U-6 basis, except for Japan.

\section{A.3 Labor Market Institutions and Income Taxation}

Countries differ greatly in terms of legislation on unions, wage setting, hours worked, and taxation. Some of these facts are reviewed in this section. In particular, given that the model described above makes use of $(i)$ varying average time between recontracting possibilities, (ii) choice of hours, (iii) taxation differences, and that, in addition, it is closely linked to other labor market institutions, the situation in the countries of interest is reviewed.

It is argued that the US is the country with the most flexible labor market characteristics and the one of the lowest level of income taxation. That the Netherlands, Belgium and the UK are flexible economies, too, but while the UK has the lowest level of taxation, the Benelux countries tax income freely. The level of flexibility on these three countries has been going up through the implementation of changes in labor market legislation. It is also argued that France and Germany exhibit low levels of flexibility together with high taxation levels. Finally Italy and Spain are countries with rigid labor markets but where we observe some willingness to get sort of flexibility.

\section{A.3.1 Labor Market Settings}

Table 8 displays data on union density, wage bargaining through collective agreements, indexes of centralization and coordination between unions, employers, and governments, fre- 
Table 8: Labor market institutions

\begin{tabular}{|c|c|c|c|c|c|c|c|c|}
\hline & Belgium & France & Germany & Netherlands & Spain & Italy & UK & US \\
\hline Union Density & 52.2 & 8.2 & 23 & 21.2 & 15.8 & 33.5 & 29 & $12.4^{\mathrm{a}}$ \\
\hline Wage Bargaining & 90 & 87 & 68 & 73 & 70 & 80 & 47 & 19 \\
\hline Centralization & 3 & 2 & 3 & 3 & 3 & 2 & 1 & 1 \\
\hline Coordination & 4 & 2 & 4 & 4 & 3 & 4 & 1 & 1 \\
\hline Bargaining frequency (years) & 1 & $1-1.5$ & $1-3$ & 0.5 & $0.5-1$ & 0.5 & 1 & No pattern \\
\hline Weekly normal hour limits & 38 & 35 & No limit & 40 & 40 & 40 & No limit & 40 \\
\hline Maximum legal weekly hours ${ }^{b}$ & 50 & 44 & 48 & 45 & 41.5 & 48 & 48 & No limit \\
\hline
\end{tabular}

Notes: Trade Union density: data from administrative sources except where stated. Data for 2003. Wage bargaining: percentage of employees covered by collective agreements as a percentage of the total number of employees. Data for 2003. Centralization and coordination: index from 1 (least centralization and coordination) to 5 (highest level of centralization and coordination). Data for 2003.

Source: OECD Employment Outlook 2004 (wage bargaining, union density, centralization and coordination), Délégation du Sénat pour l'Union Européenne (1998) (bargaining frequencies), and McCann (2005) (restrictions on hours worked, weekly normal hours, and maximum legal weekly hours).

${ }^{\mathrm{a}}$ Survey. $\quad{ }^{\mathrm{b}}$ Includes extra time.

quencies of bargaining, and restrictions on hours worked for the same set of countries.

The US is a country characterized by the highest level of flexibility on the labor market. It has the lowest level of wage bargaining (collective bargaining coverage of 19\%) among all countries considered here. Bargaining takes place exclusively at the firm level and with no particular pattern in terms of bargaining frequency. The situation is also very flexible regarding choices of hours worked. The normal work week in the US is similar to the one in the others countries but there is no legal maximum number of weekly hours. In addition, evidence from weekly hour bands indicates that most people work full time in the US, and Americans tend to work long weeks (see Figure 9). The UK may be compared to the US as this country exhibits the lowest level of wage bargaining (collective bargaining coverage of $47 \%$ ) among European countries. There is no weekly normal hours limit in that country. Negotiations take place every year but also exclusively at the firm level and with the minimum level of coordination and centralization between unions, employers and the government (as in the US). Wage bargaining at the firm level do promote employment and economic flexibility by negotiating a larger share of annual wage increases at the firm level and allowing optout clauses from central collective agreements, thus making wages more responsive to local conditions.

The UK excepted, European countries have a collective bargaining coverage greater than $68 \%$. This is true even though union density is relatively small (less than $30 \%$ in all European 
countries). Wages are defined at the national level at first, then renegotiated at the sector level in Belgium and in the Netherlands. Wage negotiation takes place within firms in France, but is sometimes framed by sectoral agreements. In Germany, wages negotiation takes place at the sector level and/or at the region level as was the case until 1994 in Spain. However, since 1994, negotiations may now occur within firms in Spain. It is finally worth noting that as in the US; bargaining takes place exclusively at the firm level in the UK, giving some flexibility to the firms on this European labor market. According to a research document from the French Senate, (Délégation du Sénat pour l'Union Européenne (1998)), negotiations take place one time during a period of one to three years in Germany, every year in Belgium and the UK, every year and a half in France and twice a year in Italy, Spain and the Netherlands while it can take place anytime in the US. The legal maximum number of weekly hours, which includes extra-time, is limited in all European countries. Data on weekly hour bands underline the fact that most people work full time in Belgium and France, as is the case in the US, that Americans and Spanish tend to work longer weeks, and that the population is spread out over most hour bands in the others countries (see Figure 9).

Apart from the frequency of negotiations, what distinguishes Belgium, Germany and the Netherlands and also more recently Spain and Italy from France is a higher level of coordination between unions, employers and the government. This coordination is worth it when the degree of centralization on the labor market is high as it is the case in Belgium, Germany and the Netherlands. This leads those countries to have a higher degree of flexibility of the labor market, even though the frequency of the negotiations in Germany is a clear limit to that flexibility. It is worth reviewing the case of the Netherlands some more. In that country, since the early 1980's, there have been important discussions between the government, the unions, and the employers which have led to a great level of coordination between all social partners. In 1982, the Wassenaar agreement marked a change in relations between Dutch unions, employers and the government. Unions agreed to more flexibility in wage setting and hours worked, and to give up resistance to part-time work. (See Nickell and van Ours (2000) for more details.) The Wassenaar agreement, as well as others that followed, have lead the unions to repeatedly accept greater flexibility in terms of choices of the working day, and to remove obstacles to part-time work. This process of improvement of flexibility is still taking place. For instance, the part-time Employment Act, passed by 
Figure 9: Weekly hours band 1985-2008 (\%)
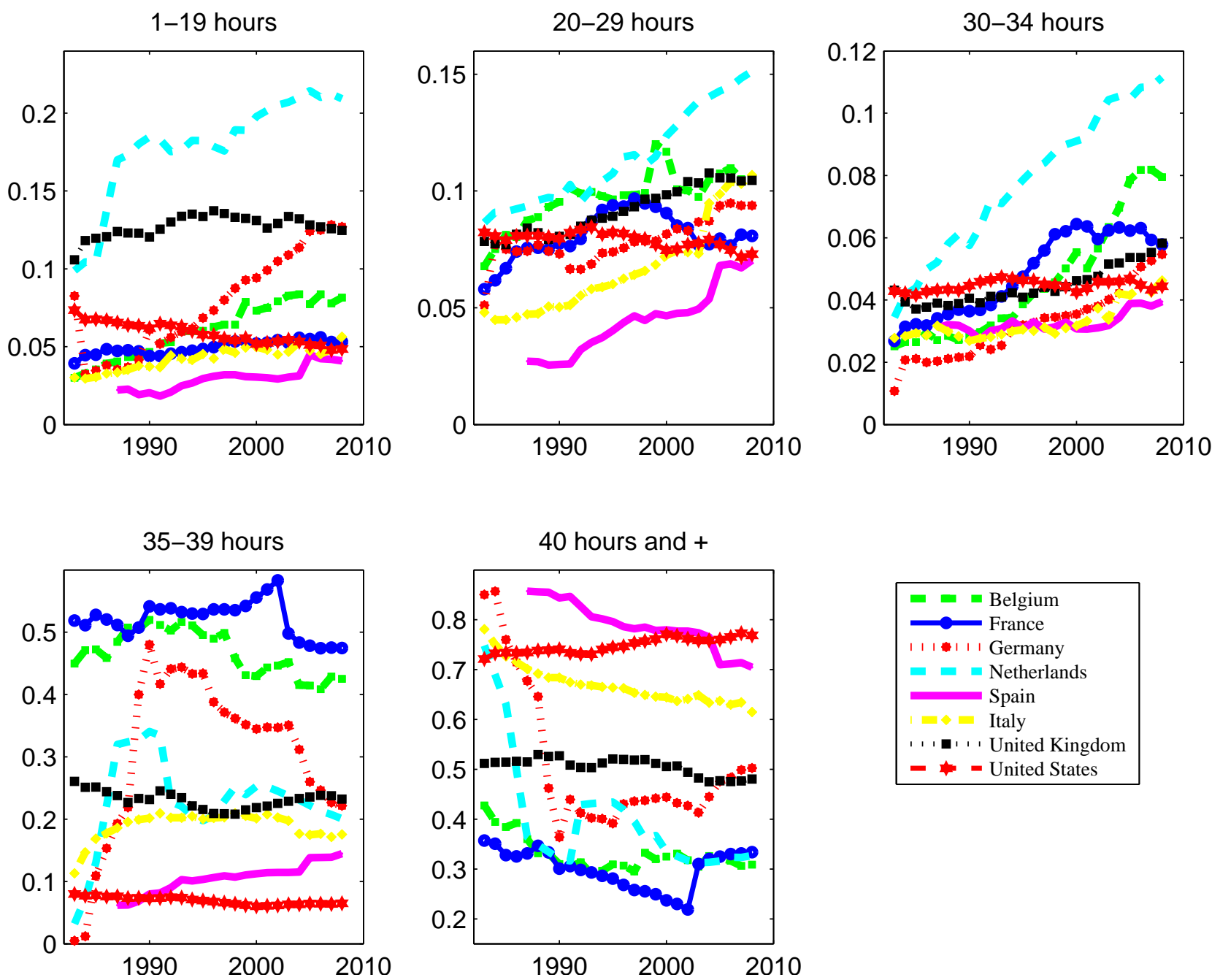

Source: OECD Statistical database. 
the lower house of the Dutch Parliament in February 2000, awards employees the right to increase or reduce their working hours. This is backed up by the survey "Doing Business 2006" of the OECD which presents an index of rigidity in OECD countries. ${ }^{18}$ While the US is categorized as a completely flexible labor market (the rigidity index is 0 for all categories) and the UK as a very flexible labor market, France, Germany and Spain count among the most rigid labor markets, and Belgium and the Netherlands, while not exempt from rigidities, are much more flexible than those countries. Taking a look at the index of rigidity in hours and in employment, for instance, the US score 0 in both, the UK scores 20 and 14 out of a maximum of 100 while France and Spain scores 60 and 56 and Germany scores 60 and 44. The three last European countries seem less rigid as Belgium scores 40 and 20, Italy scores 40 and 38 and the Netherlands score 40 and 42.

Taking into account all the information presented here leads us to argue that France, Germany Italy and Spain are the most rigid European labor markets while the US and the UK are the most flexible. Belgium and the Netherlands are intermediate cases where some flexibility do exist for different reasons.

\section{A.3.2 Labor Income Taxes}

Labor income taxation influences labor/leisure decisions of households. Prescott (2003) discusses the effects of effective marginal tax rates on labor income in Germany, France, Italy, and the US. He shows that differences in tax rates account for most of the differences in labor supply in these countries (except Italy). Effective income taxation levels are presented in Table 9. This table clearly shows that the labor income tax is much higher in Belgium, Germany, Italy, France and in the Netherlands than in the the UK and in the US. Spain could be considered as an intermediate case in Europe but still exhibits high levels of income taxation. Income taxes increase over time in all countries, and to a larger extent in Belgium, the Netherlands and in France.

\footnotetext{
${ }^{18}$ The methodology used in "Doing Business 2006" was originally developed by Botero, Djankov, LaPorta, and Lopez-De-Silanes (2004).
} 
Table 9: Effective Tax Rates on Labor Income, 1965-1997

\begin{tabular}{ccccccc}
\hline \hline Countries & $1965-1970$ & $1971-1975$ & $1976-1980$ & $1981-1985$ & $1986-1990$ & $1991-1997$ \\
\hline Belgium & - & 36.4 & 41.7 & 45.2 & 48.3 & 48.2 \\
France & 33.9 & 33.0 & 37.9 & 42.6 & 45.9 & 47.2 \\
Germany & 30.5 & 35.1 & 38.3 & 38.6 & 40.6 & 41.4 \\
Netherlands & 36.1 & 42.7 & 47.1 & 48.5 & 49.3 & 50.5 \\
Spain & - & - & - & 32.4 & 35.4 & 37.8 \\
Italy & - & - & - & 37.7 & 42.2 & 47.3 \\
UK & 22.6 & 24.7 & 26.7 & 27.5 & 25.2 & 23.7 \\
US & 20.1 & 23.0 & 25.1 & 25.3 & 25.9 & 26.7 \\
\hline \hline
\end{tabular}

Notes: Mendoza-Razin-Tesar effective tax rates updates through 1997 calculated using the method proposed in Mendoza, Razin, and Tesar (1994).

\section{B Numerical Algorithm}

To solve this model, once the functions are parameterized, we guess distributions and continuation values, solve the bargaining problem, then update distributions and value functions. More precisely: Guess $\phi, \omega$, and the term representing the continuation in $E$ and $P$ (equations 4 and 1.)

1. For each possible pairing $i, k$, solve the Nash bargaining problem. When $h$ (hours) is continuous, this implies maximizing simultaneously over $h$ and $w$. When $h$ is discreet, one can solve the NB problem for $w$ for each possible $h$ and then check which choice of hours is optimal. This yields $w_{i k}, h_{i k}$ as well as the indicator $I_{i k}$.

2. For each pair $w_{i k}, h_{i k}$, for each possible continuation $j, l$, check whether the pair remains together or not. This yields indicator function $J_{j l}(w, h)$.

3. Using indicator functions $I$ and $J$, update distributions using the equations found in Section 3.6.

4. Update value functions and continuations.

5. Check for convergence.

\section{Sensitivity Analysis}

In this appendix we give more details about the effects of changes in parameters that were covered briefly or not at all in Section 4.2. 


\section{C.1 Effects of Rigidity and of Income Taxation}

As discussed in Section 4.2.2, Figure 10 and Figure 11 confirm the unambiguity of the effects of varying rigidity on most measures of performance we use. The effect of varying income taxation on these measures can also be seen in those figures. This can also be seen in Table 3 in Section 4.2.3, which displays the usual indicators of economic performance at different tax rates for two levels of flexibility.

Figure 10: Effects of Flexibility in Contracting
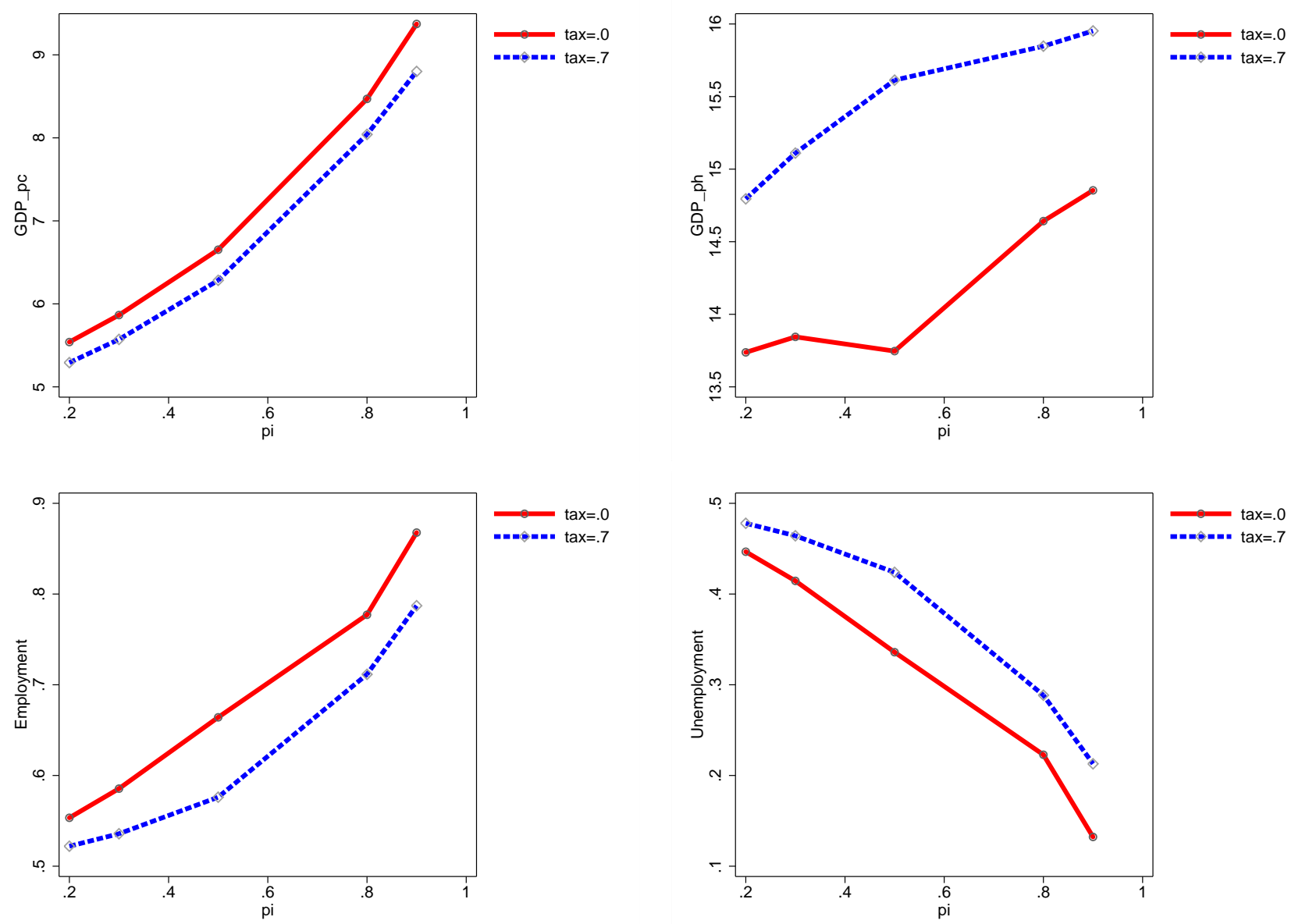

\section{C.2 Effects of Unemployment Insurance}

As mentioned in Section 4.2, unemployment insurance either has very little effects or enormous ones. We introduce it as a lump-sum transfer $b$ given to all unemployed workers, irrespective of their type. As long as $b$ is less than the minimum wage, the UI has only very marginal effects on the results, as can be seen in Table 10. When the benefit is greater than 
Figure 11: Effects of Flexibility in Contracting

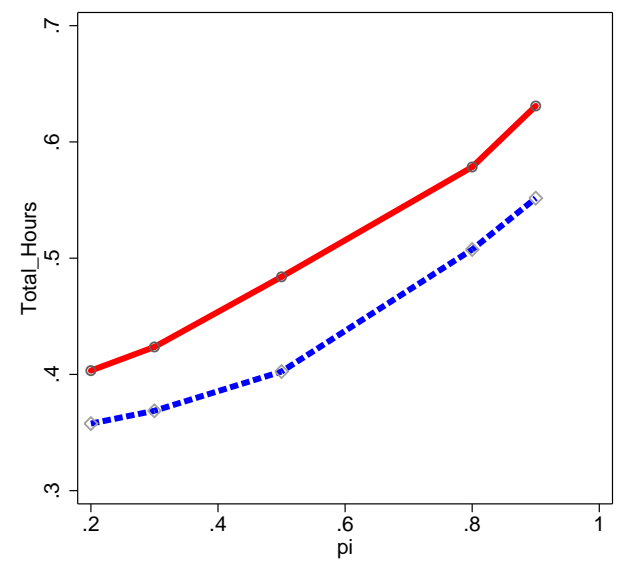

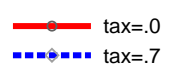

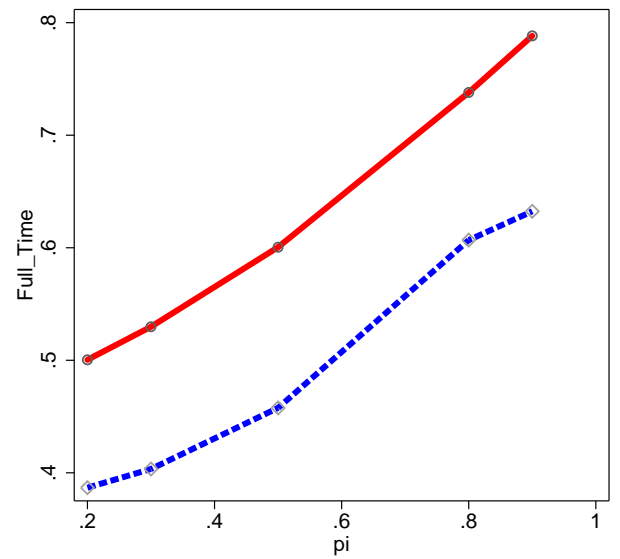

$\operatorname{tax}=.0$
$\operatorname{tax}=.7$

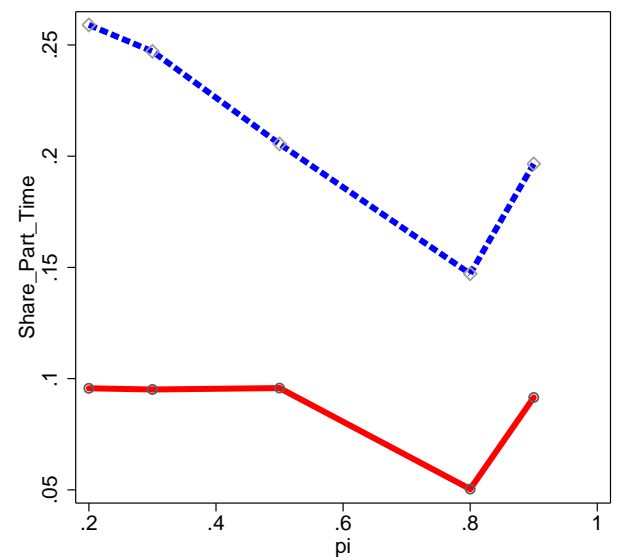

$\operatorname{tax}=.0$

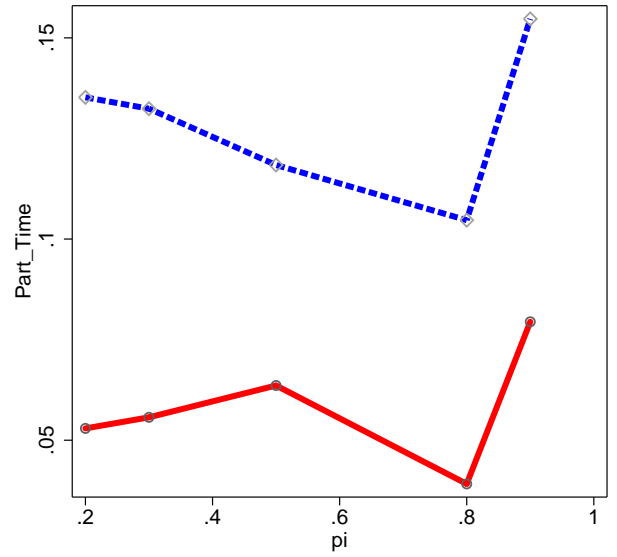

tax $=.0$
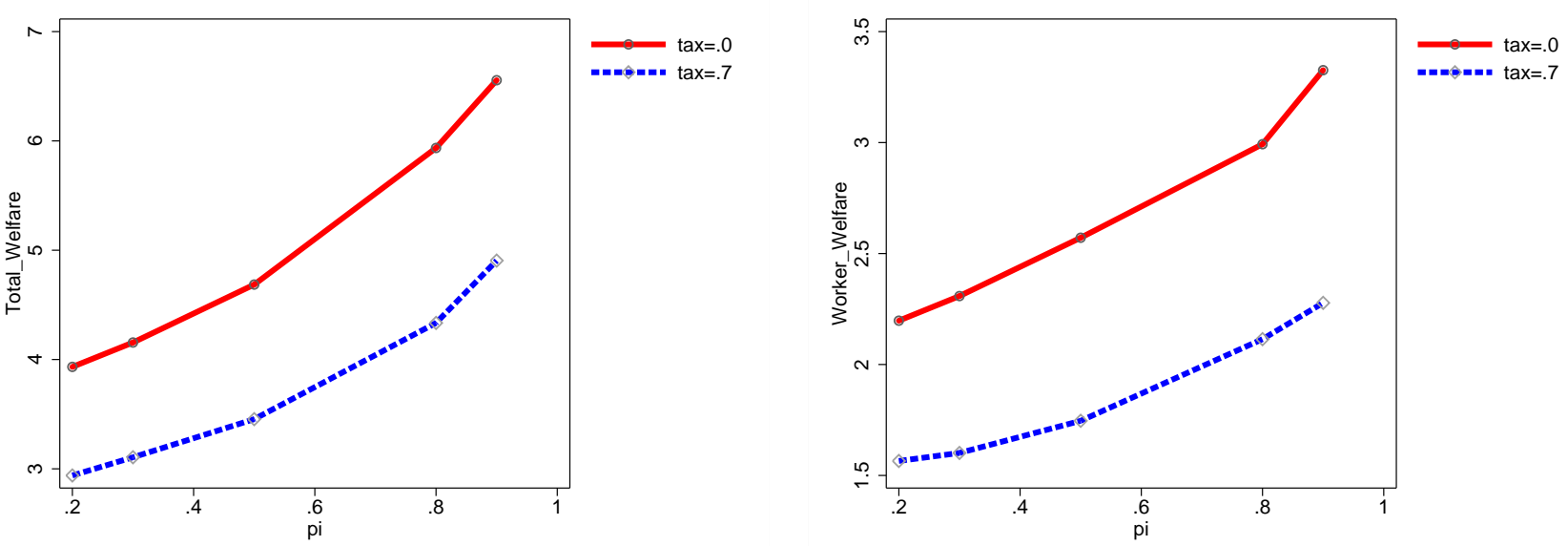
the minimum wage encountered in the economy, it basically increases unemployment by the mass of workers earning $w$ sufficiently close to $b$. In this case, workers do not accept matches in which the wage comes close to unemployment benefit payment, even if they are higher, unless there is a high likelihood that the productivity of the match increases sufficiently in the future to compensate, which is rare. It should be noted that UI has no direct effects on part-time work, as it is perceived only by unemployed workers. However, it does increase the part-time share slightly, especially when flexibility is high, as it increases the outside option of workers in the bargaining.

Table 10: Effects of unemployment insurance

\begin{tabular}{l|c|cccc}
\hline \hline$\pi$ & b & GDP per capita & GDP per hour & Unemployment & Part-time share \\
\hline 0.3 & & & & & \\
& 0.0 & 5.865 & 13.844 & 0.415 & 0.095 \\
& 0.2 & 5.865 & 13.844 & 0.417 & 0.095 \\
& 0.4 & 5.863 & 13.865 & 0.418 & 0.096 \\
& 0.6 & 5.863 & 13.865 & 0.419 & 0.096 \\
& 0.8 & 5.858 & 13.913 & 0.420 & 0.097 \\
\hline 0.9 & & & & & \\
& 0.0 & 9.372 & 14.854 & 0.132 & 0.092 \\
& 0.2 & 9.383 & 14.856 & 0.132 & 0.103 \\
& 0.4 & 9.383 & 14.856 & 0.132 & 0.115 \\
& 0.6 & 9.379 & 14.886 & 0.133 & 0.116 \\
& 0.8 & 9.367 & 14.887 & 0.134 & 0.117 \\
\hline \hline
\end{tabular}

\section{C.3 Effects of Risk Aversion}

The parameter of risk aversion, $\sigma$ has important effects in our economy, effects that vary depending on the level of flexibility. When $\sigma$ is sufficiently high, workers do not wish to remain unemployed long, and tend to be less picky, matching with lower types of firms. As a consequence, decreasing risk aversion $\sigma$ leads to an increase in unemployment, thus a decrease in employment, a decrease in GDP per capita, an increase in GDP per hour and a decrease in the share of part-time jobs. This is summarized in Table 11.

\section{C.4 Effects of Leisure Preference Parameters}

An increase in $a$ (Table 12) increases the weight of leisure time in the utility function. Effects of such a change on our economy are totally expected. Unemployment increases and the share of part-time jobs increases, this has a negative effect on GDP per capita. While it 
Table 11: Effects of changes in $\sigma$

\begin{tabular}{l|c|cccc}
\hline \hline$\pi$ & $\sigma$ & GDP per capita & GDP per hour & Unemployment & Part-time share \\
0.3 & & & & & \\
& 0.4 & 5.953 & 10.647 & 0.492 & 0.051 \\
& 1 & 5.865 & 13.844 & 0.415 & 0.095 \\
\hline 0.9 & & & & & \\
& 0.4 & 11.811 & 13.282 & 0.368 & 0.074 \\
& 1 & 9.372 & 14.854 & 0.132 & 0.092 \\
\hline \hline
\end{tabular}

could potentially have a positive or a negative effect on GDP per hour, depending on how much sorting is brought up by the increase in unemployment, it turns out to have a positive effect in all our simulations, including the ones with low risk aversion and high flexibility in which unemployment increases the most. Increasing $\nu$ (Table 13), thus decreasing marginally the returns to leisure, leads to decreased GDP per capita, increased GDP per hour, and an increased share of part-time. The effect on unemployment depends on flexibility. In a rigid economy, increasing $\nu$ leads to a tiny increase in unemployment. In a flexible economy, it leads to a very slight decrease in unemployment.

Table 12: Effects of changes in $a$

\begin{tabular}{l|c|cccc}
\hline \hline$\pi$ & $a$ & GDP per capita & GDP per hour & Unemployment & Part-time share \\
\hline 0.3 & & & & & \\
& 0.5 & 5.865 & 13.844 & 0.415 & 0.095 \\
& 1.5 & 5.227 & 181.779 & 0.528 & 0.492 \\
& 2.5 & 4.285 & 224.196 & 0.537 & 1 \\
\hline 0.9 & & & & & \\
& 0.5 & 9.372 & 14.854 & 0.132 & 0.092 \\
& 1.5 & 8.735 & 18.023 & 0.224 & 0.397 \\
& 2.5 & 7.102 & 22.767 & 0.259 & 1 \\
\hline \hline
\end{tabular}

Table 13: Effects of changes in $\nu$

\begin{tabular}{l|c|cccc}
\hline \hline$\pi$ & $\nu$ & GDP per capita & GDP per hour & Unemployment & Part-time share \\
\hline 0.3 & & & & & \\
& 0.5 & 5.947 & 13.046 & 0.412 & 0.020 \\
& 0.8 & 5.865 & 13.844 & 0.415 & 0.095 \\
\hline 0.9 & & & & & \\
& 0.5 & 9.465 & 14.103 & 0.133 & 0.000 \\
& 0.8 & 9.372 & 14.854 & 0.132 & 0.091 \\
\hline \hline
\end{tabular}




\section{C.5 Effects of Shock Parameters}

The effects of flexibility remains similar for various values of the persistence of the shock process. As can be seen in Table 14, GDP per capita increases, GDP per hour increases or decreases, depending on persistence, unemployment decreases and the share of part-time increases or decreases, depending on persistence.

The impact of a change in persistence is also summarized in Table 14. The main effect of increasing persistence is to lead to more sorting in equilibrium. Intuitively, at lower persistence levels, today's productivity does not allow to predict well next period's productivity, and thus the future value of a match comes closer to the value of search, leading individuals to be less picky. This can be seen clearly by looking at GDP per capita and unemployment in the table. Higher persistence leads both to higher GDP per capita and higher unemployment. Low productivity matches tend to disappear, and productivity in the economy, as measured by GDP per hour, increases. The share of part-time jobs also increases with persistence. For the same reason leading individuals to be less picky when there is lower persistence, taxation has only a small effect on economic performance for $\rho<0.99$. Increasing the variance of the shock, $\epsilon$ results in increases of GDP per capita and GDP per hour, a very slight increase in unemployment, and a slight decrease in the share of part-time, as can be seen in Table 15 .

Table 14: Effects of changes in $\rho$

\begin{tabular}{l|c|cccc}
\hline \hline$\pi$ & $\rho$ & GDP per capita & GDP per hour & Unemployment & Part-time share \\
\hline 0.3 & & & & & \\
& 0.85 & 2.564 & 4.753 & 0.302 & 0.013 \\
& 0.95 & 3.318 & 7.729 & 0.407 & 0.027 \\
& 0.99 & 5.865 & 13.844 & 0.415 & 0.095 \\
\hline 0.9 & & & & & \\
& 0.85 & 3.399 & 4.898 & 0.075 & 0.015 \\
& 0.95 & 5.009 & 7.458 & 0.090 & 0.035 \\
& 0.99 & 9.372 & 14.854 & 0.132 & 0.092 \\
\hline \hline
\end{tabular}

Table 15: Effects of changes in $\epsilon$

\begin{tabular}{l|c|cccc}
\hline \hline$\pi$ & $\epsilon$ & GDP per capita & GDP per hour & Unemployment & Part-time share \\
\hline 0.9 & & & & & \\
& 0.2 & 9.372 & 14.854 & 0.132 & 0.092 \\
& 0.3 & 11.493 & 16.986 & 0.134 & 0.091 \\
& 0.4 & 13.149 & 19.477 & 0.136 & 0.080 \\
\hline \hline
\end{tabular}




\section{C.6 Change in the Bargaining Power}

A change in the bargaining power does not affect the effects of variations in $\pi$ and policies on the economy (see Table 16). It does have interesting effects of its own. Increasing the bargaining power of the workers leads to a higher share of part-time and a lower unemployment rate. The effects on GDP per capita and GDP per hour depend on flexibility, however. In an economy with a high degree of flexibility, more power to the workers leads to a lower GDP per capita but a higher GDP per hour. The reverse is true in a rigid economy.

Table 16: Effects of changes in $\eta$

\begin{tabular}{l|c|cccc}
\hline \hline$\pi$ & $\eta$ & GDP per capita & GDP per hour & Unemployment & Part-time share \\
\hline 0.3 & & & & & \\
& 0.5 & 5.81696 & 14.1398 & 0.459 & 0.022 \\
& 0.7 & 5.86508 & 13.8444 & 0.414 & 0.095 \\
\hline 0.9 & & & & & \\
& 0.5 & 9.50687 & 14.1221 & 0.133 & 0.014 \\
& 0.7 & 9.37195 & 14.8539 & 0.132 & 0.091 \\
\hline \hline
\end{tabular}

\section{C.7 Change in the Remaining Parameters}

Changes in the remaining parameters $(\beta, \alpha, \mu)$ do not change the effects of variations in flexibility, and have expected effects on economic performance. A decrease in the discount rate $\beta$ results in a decrease in unemployment and an increase in the share of part-time. GDP per capita increases but GDP per hour decreases.

An increase in the worker share in the production function, $\alpha$, results in a lowering of unemployment and of the share of part-time, which translates in an increase in GDP per capita and a lowering of GDP per hour.

Finally, lowering the returns to hours worked, $\mu$, yields an increase in the share of parttime jobs, an increase in unemployment, a decrease in GDP per capita and a decrease in GDP per hour. 